Document downloaded from:

http://hdl.handle.net/10251/147687

This paper must be cited as:

Sanchis Martinez, R.; Cecilia, J.; Soriano Rodríguez, MD.; Vazquez, I.; Dejoz, A.; López Nieto, JM.; Rodriguez-Castellon, E.... (2008). Porous clays heterostructures as supports of iron oxide for environmental catalysis. Chemical Engineering Journal. 334:1159-1168. https://doi.org/10.1016/j.cej.2017.11.060

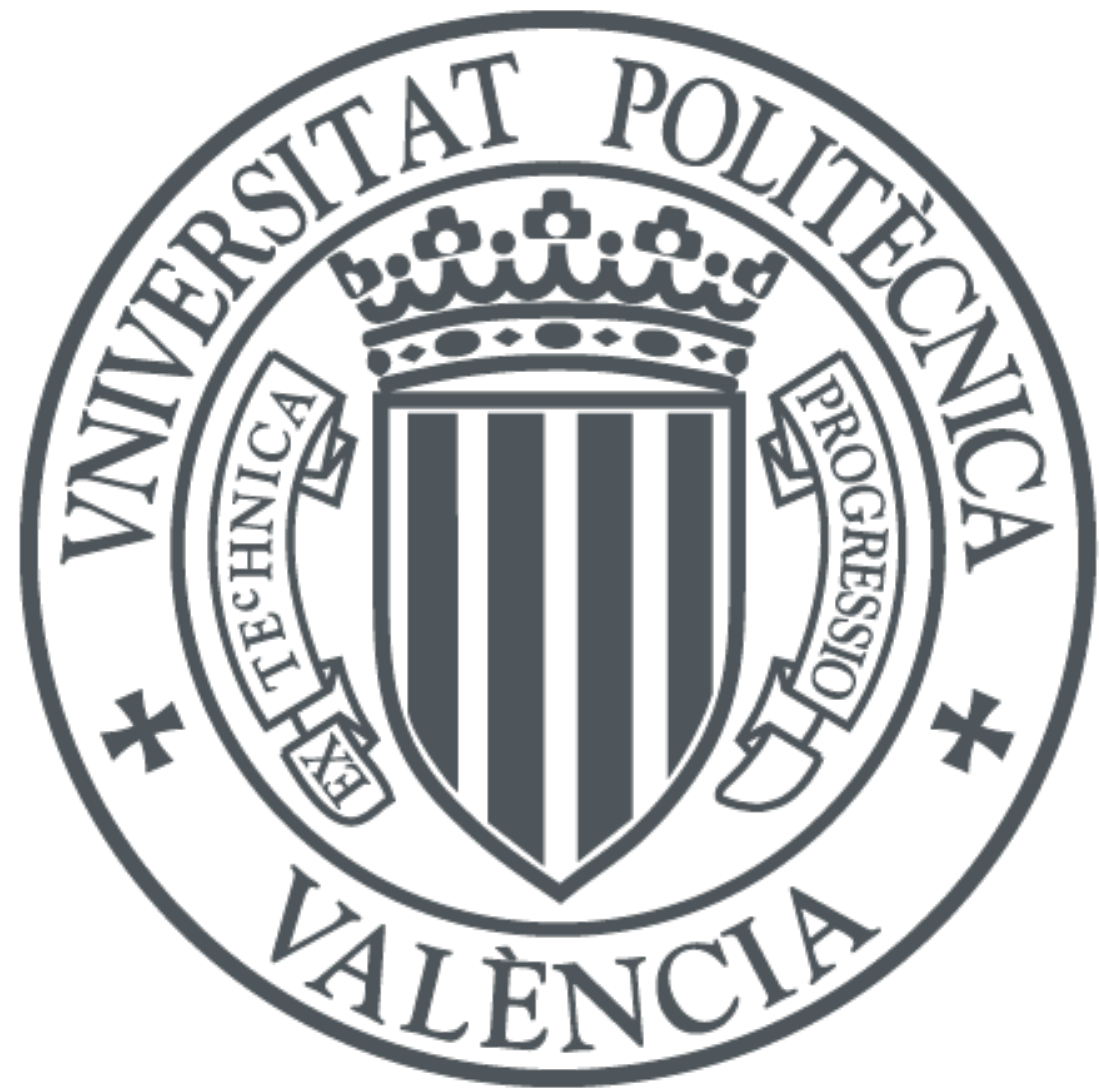

The final publication is available at

https://doi.org/10.1016/j.cej.2017.11.060

Copyright Elsevier

Additional Information 


\section{Accepted Manuscript}

Porous Clays Heterostructures as supports of iron oxide for environmental catalysis

R. Sanchis, J.A. Cecilia, M.D. Soriano, M.I. Vázquez, A. Dejoz, J.M. López

Nieto, E. Rodríguez Castellón, B. Solsona

PII:

S1385-8947(17)31968-X

DOI: https://doi.org/10.1016/j.cej.2017.11.060

Reference:

CEJ 18031

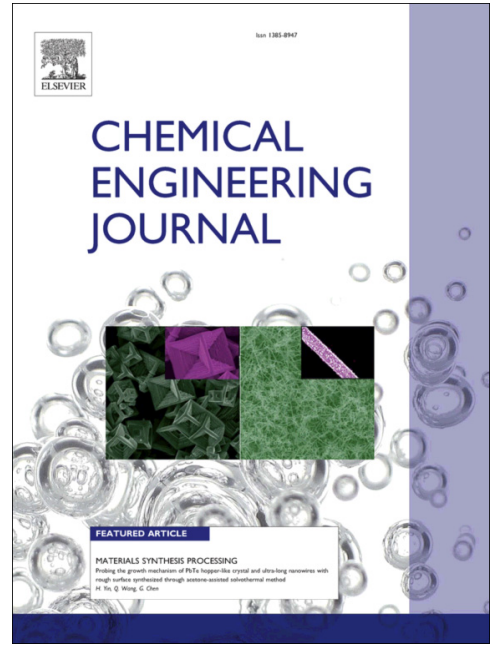

To appear in:

Chemical Engineering Journal

Received Date:

25 July 2017

Revised Date:

7 November 2017

Accepted Date:

11 November 2017

Please cite this article as: R. Sanchis, J.A. Cecilia, M.D. Soriano, M.I. Vázquez, A. Dejoz, J.M. López Nieto, E. Rodríguez Castellón, B. Solsona, Porous Clays Heterostructures as supports of iron oxide for environmental catalysis, Chemical Engineering Journal (2017), doi: https://doi.org/10.1016/j.cej.2017.11.060

This is a PDF file of an unedited manuscript that has been accepted for publication. As a service to our customers we are providing this early version of the manuscript. The manuscript will undergo copyediting, typesetting, and review of the resulting proof before it is published in its final form. Please note that during the production process errors may be discovered which could affect the content, and all legal disclaimers that apply to the journal pertain. 


\title{
Porous Clays Heterostructures as supports of iron oxide for environmental
} catalysis

\author{
R. Sanchis ${ }^{1}$, J.A. Cecilia ${ }^{2}$, M. D. Soriano ${ }^{2,3}$, M.I. Vázquez ${ }^{1}$, A. Dejoz ${ }^{1}$, J.M. López \\ Nieto $^{3, *}$, E. Rodríguez Castellón ${ }^{2}$, B. Solsona ${ }^{1, *}$
}

${ }^{1}$ Departament d'Enginyeria Química, Universitat de València, C/ Dr. Moliner 50, 46100 Burjassot, Valencia, Spain. Email: benjamin.solsona@uv.es

${ }^{2}$ Departamento de Química Inorgánica, Facultad de Ciencias, Universidad de Málaga, 29071 Málaga, Spain

${ }^{3}$ Instituto de Tecnología Química, Universitat Politècnica de València-Consejo Superior de Investigaciones Científicas, Avenida de los Naranjos s/n, 46022 Valencia, Spain. Email: jmlopez@itq.upv.es

\footnotetext{
* To whom correspondence should be addressed
} 


\section{Abstract}

Porous Clays Heterostructures ( $\mathrm{PCH}$ ) from natural pillared clays (bentonite with a high proportion of montmorillonite) have been used as supports of iron oxide for two reactions of environmental interest: i) the elimination of toluene (a representative compound of one of the most toxic subsets of volatile organic compounds, aromatics) by total oxidation and ii) the selective oxidation of $\mathrm{H}_{2} \mathrm{~S}$ to elemental sulfur. For both reactions these catalysts have resulted to be remarkably more efficient than similar catalysts prepared using conventional silica as a support. Thus, in the total oxidation of toluene it has been observed that the catalytic activity obtained using siliceous PCH is two orders of magnitude higher than that with conventional silica. The catalytic activity has shown to be dependant of the capacity of the support for dispersing iron oxide in a way that the higher the dispersion of iron oxide on the surface of the support, the higher is the activity. In the case of the selective oxidation of $\mathrm{H}_{2} \mathrm{~S}$ to $\mathrm{S}$ both higher catalytic activity and higher selectivity to $\mathrm{S}$ have been observed using siliceous porous clays heterostructures than using conventional silica. Highly dispersed FeOx species have been shown as highly selective towards elemental sulfur whereas more aggregated $\mathrm{FeOx}$ species favour the formation of sulphur oxides decreasing the selectivity to S. Analyses of the surface by XPS have shown the predominance of sulfate species in the catalysts presenting low selectivity to elemental sulfur.

Keywords: $\mathrm{H}_{2} \mathrm{~S}$ to $\mathrm{S}$; toluene; total and selective oxidation; iron oxide; VOC; Porous Clays Heterostructures $(\mathrm{PCH})$. 


\section{INTRODUCTION}

Nowadays there are several technologies in use for the elimination of volatile organic compounds (VOCs). These technologies can be divided into two main groups: i) those that remove VOCs without destroying them and ii) those which eliminate them by destroying them. In the first group, we can highlight adsorption and absorption. Both processes are relatively easy and the energy consumption associated to these techniques is usually low. However, they do not remove VOCs to very low levels and its potential is limited by the capacity of the adsorption/absorption media.

In the second group thermal and catalytic oxidation are also well established treatment technologies. Thermal combustion is a simple method of control that usually needs temperatures over $900^{\circ} \mathrm{C}$, requiring important energy input and generating in many cases undesirable by-products. These drawbacks can be sorted out through heterogeneous catalytic oxidation, which offers many potential advantages, decreasing the operational temperature as well as the amount of by-products formed [1].

The term VOCs includes many compounds with distinct chemical functionality. Aromatic compounds represent one of the subset with highest toxicity [1, 2]. Most of catalysts used for VOCs abatement through total oxidation present noble metals (NM) in its composition, especially Pd and/or Pt [3,4]. Other oxides of non-NM, such as those of cobalt $[5,6,7]$, manganese $[5,8,9]$ and iron are promising alternatives since they present high reactivity and low price [10]. Unfortunately, the reactivity of these oxides is lower than that of the most efficient NM-based catalysts. The case of iron oxide is especially notorious since it is among these non-NM oxides the cheapest, the most abundant and environmentally friendly. Another advantage of iron oxide is the high temperature at which sintering takes place, then preventing or mitigating deactivation. In any case, the calcination and the reaction temperatures must be controlled to avoid stability problems [11]. 
Sazonov et al. [12] reported that the reaction rate for methane oxidation only depend on the amount of iron, suggesting that the role of the crystallite size and the dispersion degree of iron oxide is limited. In contrast, Zhang et al. [13] observed in toluene oxidation on Fe/SBA-15 catalysts that dispersed iron oxide species were more reducible than aggregated species, and this better dispersion led to higher activity. Recently, it has been reported that unsupported iron oxide synthesized by nanocasting presenting high surface area $\left(>200 \mathrm{~m}^{2} \mathrm{~g}^{-1}\right)$ shows remarkable activity for toluene oxidation [13]. A connection between reducibility of the Fesites and the reaction was not observed.

Using iron oxide supported on silica it was observed that the activity increases with the iron loading but the reaction rate per iron site decreased, suggesting that dispersion is a determining factor to achieve high conversions. Another positive aspect of iron oxide catalysts is its high selectivity towards $\mathrm{CO}_{2}$ as it was almost exclusively formed if the iron loading exceeded 1 wt.\% [14]. Moreover, it has also been described that iron oxide can be an efficient promoter, for example of manganese oxide [15].

Several metals and metals oxides have been also studied as active phase for the partial oxidation of $\mathrm{H}_{2} \mathrm{~S}$ to sulfur, in which $\mathrm{SO}_{2}$ is formed as a by-product, by the $\mathrm{H}_{2} \mathrm{~S}$ combustion reaction [16]. In this way, iron oxides based catalysts seem to be also very interesting catalysts since they can show high selectivity to partial oxidation reaction. [17-20]. In most of these cases, supported iron oxide have been studied and the support can have an important promoter effect since they can modify the characteristics of iron oxide particles and the catalytic performance.

Clay minerals present lamellar structures with high versatility which can be used as absorbents, ion exchangers or catalysts. The physicochemical characteristics of these clay minerals may be improved by the insertion of polyoxocations leading to pillared interlayered clays (PILC) [21] or by the insertion of a bulky cation and the subsequent formation of pillars 
between adjacent layers, obtaining a porous clay heterostructure $(\mathrm{PCH})$ [22]. The synthesis of PCH generates structures with tunable porosity, higher surface area and higher thermal and mechanical stability than PILC [22]. This fact leads to structures potentially optimal to be used as catalytic support [23].

Summarizing, in the present work we have studied the catalytic performance of a set of iron oxide catalysts supported on porous clays heterostructures in two important reactions from an environmental viewpoint:

i) the total oxidation of a representative volatile organic compound as toluene

$$
\mathrm{C}_{7} \mathrm{H}_{8}+9 \mathrm{O}_{2} \rightarrow 7 \mathrm{CO}_{2}+4 \mathrm{H}_{2} \mathrm{O}
$$

ii) the removal of $\mathrm{H}_{2} \mathrm{~S}$ by oxidation to elemental sulphur.

$$
\begin{aligned}
& \mathrm{H}_{2} \mathrm{~S}+1 / 2 \mathrm{O}_{2} \rightarrow \mathrm{S}+\mathrm{H}_{2} \mathrm{O} \text { (desired reaction) } \\
& \mathrm{H}_{2} \mathrm{~S}+1.5 \mathrm{O}_{2} \rightarrow \mathrm{SO}_{2}+\mathrm{H}_{2} \mathrm{O} \text { (undesired reaction) }
\end{aligned}
$$

For comparison, iron oxide on commercial silica was also tested. Overall, we want to determine the importance of the characteristics of the support (surface area and composition) on the dispersion of iron oxide and especially on the catalytic performance. In addition, the influence of the iron loading has also been discussed. Three different iron loadings have been used in two different supports: conventional amorphous silica and high surface area pillared silica. The catalysts have been characterized by several techniques and the catalytic results have been interpreted on the basis of the characterization data.

\section{Experimental}

\subsection{Preparation of the pillared clay support}

The porous clay heterostructure (PCH) supports have been prepared from bentonite, with high amount of montmorillonite. The mineral has been drawn from "Sierra de Nijar" in Spain. This 
material was provided by Minas de Gador S.A. Before the preparation of $\mathrm{PCH}$, the montmorillonite was isolated through sedimentation and then treated with a $\mathrm{NaCl}$ aqueous solution for $24 \mathrm{~h}$ to get homoionic montmorillonate (Na-hm).

Na-hm ( $5 \mathrm{~g})$ was treated with a saturated solution of hexadecyl trimethyl ammonium bromide (27g) (HDTMBr, from Sigma-Aldrich) in $n$-propanol (200 ml) (from VWR). This way ionic exchange between $\mathrm{HDTM}^{+}$and $\mathrm{Na}^{+}$as well as an expansion of the spacing of the interlayer took place. After $72 \mathrm{~h}$, the mixture was filtered up to neutral $\mathrm{pH}$ was obtained in order to eliminate the excess of $\mathrm{HDTM}^{+}$. Then, the solid was collected and re-dispersed (in $500 \mathrm{ml}$ of water for $24 \mathrm{~h})$. Next, a solution of 1-hexadecylamine (1.8 g) in $n$-propanol (50 ml) was added to the former solution and was stirred for $24 \mathrm{~h}$. Si-pillars were dispersed in a solution of $n$ propanol with a ratio $\mathrm{Si} / n$-propanol of 1 and stirred for 3 days. In this case, tetraethyl orthosilicate (Aldrich) was used as the silicon source. The gel obtained was filtered and washed using ethanol and water. The solid was then dried in air at $60{ }^{\circ} \mathrm{C}$ for $12 \mathrm{~h}$. Finally the solid was calcined at $550{ }^{\circ} \mathrm{C}$ (rate of $1{ }^{\circ} \mathrm{C} \mathrm{min}-1-6 \mathrm{~h}$ ) in order to remove the surfactant. The final PCH material presents a surface area of $644 \mathrm{~m}^{2} \mathrm{~g}^{-1}$.

For comparison, a conyentional amorphous silica (Silica Aerosil, $\mathrm{S}_{\mathrm{BET}}=181 \mathrm{~m}^{2} \mathrm{~g}^{-1}$ ) has been also used as support.

\subsection{Preparation of supported iron oxide catalysts}

Fe supported catalysts were prepared by the wet impregnation method using porous clays heterostructures with columns of silica $(\mathrm{PCH})$ or conventional amorphous silica $\left(\mathrm{SiO}_{2}\right)$ as supports. Solutions of iron (II) nitrate were dissolved in water and added to the support. After stirring at $80^{\circ} \mathrm{C}$ the evaporation of water led to the formation of a wet paste. This paste was dried overnight at $120^{\circ} \mathrm{C}$ and then calcined in air at $500^{\circ} \mathrm{C}$ for $4 \mathrm{~h}$. Supported catalysts, on both high surface area porous clays heterostructures with columns of silica $(\mathrm{PCH})$ or 
conventional amorphous silica, have been prepared with $4.4,8.5$ and 15.6 wt.\% of Fe. The catalysts have been named as $\mathrm{xFe} / \mathrm{PCH}$ and $\mathrm{xFe} / \mathrm{Si}$, respectively, in which $\mathrm{x}$ is the Fe-content in wt\% of iron. The characteristics of the supports and catalysts are described in Table 1.

For a comparative purpose, a commercial unsupported $\mathrm{Fe}_{2} \mathrm{O}_{3}$ supplied from Panreac and calcined at $500^{\circ} \mathrm{C}$ for $4 \mathrm{~h}$ was tested in toluene oxidation. This catalyst presents a surface area of $3.3 \mathrm{~m}^{2} \mathrm{~g}^{-1}$.

\subsection{Characterization techniques}

The surface areas of the catalysts have been determined using multi-point $\mathrm{N}_{2}$ adsorption at $196{ }^{\circ} \mathrm{C}$. The BET method was applied to obtain the surface area data. X-ray diffraction (powder XRD) was employed to know the nature of the crystalline phases present in the samples. An Enraf Nonius FR590 sealed tube diffractometer, with a monochromatic $\mathrm{CuK}_{\alpha 1}$ source operated at $40 \mathrm{kV}$ and $30 \mathrm{~mA}$ was used. Silicon was used as the standard for calibration.

Temperature programmed reduction (TPR) was conducted using a Micromeritics Autochem 2910 apparatus equipped with a Thermal Conductivity Detector. The reducing gas employed was hydrogen $\left(10 \mathrm{~mol} \% \mathrm{H}_{2}\right.$ in Ar) and the total flow rate was fixed in $50 \mathrm{ml} \mathrm{min}^{-1}$ (GHSV ca. $8000 \mathrm{~h}^{-1}$ ). The range of temperatures explored was from $20^{\circ} \mathrm{C}$ to $900{ }^{\circ} \mathrm{C}$ using a heating rate of $10{ }^{\circ} \mathrm{C} \mathrm{min}^{-1}$.

Structural and morphological characterization of the catalysts was carried out by Transmission Electron Microscopy (TEM), high resolution TEM (HRTEM) and selected Area electron diffraction (SAED) by using a FEI Field Emission Gun (FEG) TECNAI G2 F20 STWIN microscope operated at $200 \mathrm{kV}$. Energy Dispersive x-rays Spectroscopy (EDS) in TEM nanoprobe mode was used to check the purity of the synthesized iron oxide particles. The iron oxide powder catalysts were sonicated in pure ethanol for several minutes. Finally, a 
drop of this suspension was left over a holey-carbon film supported on a $\mathrm{Cu}$ grid, and then it was dried.

XPS data were collected using a Physical Electronics PHI 5700 spectrometer with nonmonochromatic $\mathrm{Mg}-\mathrm{K} \alpha$ radiation $(300 \mathrm{~W}, 15 \mathrm{kV}, 1253.6 \mathrm{eV})$ for the analysis of the core level signals of the elements and with a multichannel detector. Spectra of the catalysts were obtained with constant pass energy values at $29.35 \mathrm{eV}$, using a $720 \mu \mathrm{m}$ diameter analysis area. The spectrometer energy scale was calibrated using $\mathrm{Au} 4 f_{7 / 2}, \mathrm{Ag} 3 d_{5 / 2}$ and $\mathrm{Cu} 2 p_{3 / 2}$ with photoelectron lines at 84.0, 368.3 and $932.7 \mathrm{eV}$, respectively. For acquisition and data analysis, the PHI ACCESS ESCA-V6.F software package was employed. The spectra registered were fitted adjusting to Gauss-Lorentz curves, to get an accurate determination of the binding energy.

Diffuse reflectance UV-Vis spectra were collected on a UV-2600 Shimadzu equipped with a "Praying Mantis" attachment from Harrick. The sample cell was equipped with a heater unit, a thermocouple, and a gas flow system for in situ measurements. The samples were dehydrated in situ in dry air at $150^{\circ} \mathrm{C}$ for $30 \mathrm{~min}$.

\subsection{Catalyst activity determination}

Catalytic activity in toluene oxidation was measured using a fixed bed laboratory microreactor. The feed used consisted of $1000 \mathrm{vppm}$ of toluene in synthetic air $\left(20 \% \mathrm{O}_{2}\right.$ in $\left.\mathrm{He}\right)$ with a space velocity, GHSV, of $30000 \mathrm{~h}^{-1}$. Reactants and reaction products were analysed online by gas chromatography using TCD and FID detectors. Two chromatographic columns were used: i) Porapak Q (for hydrocarbons and $\mathrm{CO}_{2}$ ) and ii) Molecular Sieve 5A (to split $\mathrm{O}_{2}, \mathrm{~N}_{2}$ and $\mathrm{CO}$ ). The reaction temperature was measured using a thermocouple placed in the catalyst bed. The catalytic experiments were carried out in the $100-325^{\circ} \mathrm{C}$ range. Conversion data were calculated comparing the inlet and outlet concentrations of toluene. On the other hand, the 
evolution of the area of $\mathrm{CO}_{2}$ was increased as the toluene area was decreasing, providing a comparative conversion data. The carbon balance presents in all cases an accuracy of $\pm 4 \%$. Before each analysis, we ensured a steady state activity (30 minutes). Then, two analyses were conducted at each temperature and their results averaged. Negligible conversion was obtained in the absence of catalyst at temperatures of $500^{\circ} \mathrm{C}$ and below.

Catalytic experiments for the partial oxidation of hydrogen sulfide were carried out in a fixedbed quartz tubular flow reactor at atmospheric pressure. We want to note that the reactivity observed for $\mathrm{Fe} / \mathrm{PCH}$ catalysts is remarkably higher than that obtained with $\mathrm{Fe} / \mathrm{Si}$ catalysts. As the selectivity to $\mathrm{S}$ and $\mathrm{SO}_{2}$ are strongly dependent on the $\mathrm{H}_{2} \mathrm{~S}$ conversion, for a proper comparison of the selectivity it is necessary to work at similar $\mathrm{H}_{2} \mathrm{~S}$ conversions. For this reason we used double amount of Fe/Si catalysts $(0.2 \mathrm{~g})$ than that of $\mathrm{Fe} / \mathrm{PCH}$ catalysts $(0.1 \mathrm{~g})$, this way achieving similar conversions and then making possible a suitable comparison of the selectivity. In both cases, the catalysts were mixed with silicon carbide as inert (1:5 weight catalyst/SiC) for having an adequate bed height. A feed mixture composed of $\mathrm{H}_{2} \mathrm{~S} / \mathrm{Air} / \mathrm{He}$ (1.2/5.0/93.8 molar ratio) and a total flow of $130 \mathrm{ml} \mathrm{min}^{-1}$. Analysis of reactants and products was carried out on-line by gas chromatography using two different chromatographic columns: i) Porapak T, and ii) Molecular Sieve $5 \AA$ [20]. An additional experiment was undertaken using only silicon carbide in order to confirm that the catalytic performance is only due to the presence of the iron catalysts. Blank experiment with $\mathrm{SiC}$ at the reaction conditions used in this study $\left(\mathrm{ca}\right.$. temperature of $180^{\circ} \mathrm{C}$ ) shows a $\mathrm{H}_{2} \mathrm{~S}$ conversion of $0.5 \%$. Accordingly, no influence of $\mathrm{SiC}$ on catalytic performance can be proposed.

\section{Results}

\subsection{Characterization of catalysts}


Table 1 shows the physicochemical characteristics of supported iron oxide based catalysts. The surface area of supported catalysts depends on the support used and on the iron content. Then, the catalysts supported on $\mathrm{PCH}$ present a surface area in the $394-474 \mathrm{~m}^{2} \mathrm{~g}^{-1}$ range; whereas those supported conventional silica present a lower surface area (in the $150-171 \mathrm{~m}^{2} \mathrm{~g}$

${ }^{1}$ range). As expected, the surface area of the catalysts decreased with the iron loading of the catalyst.

Figure 1 shows the XRD patterns of supported iron oxide catalysts. In the catalysts supported on $\mathrm{PCH}$, it can be seen a rather amorphous pattern with the presence of low intensity peaks at $2 \theta=20,27.8$ and $35.3^{\circ}$ which are associated to the support (Fig. 1). A different behaviour is observed for $\mathrm{SiO}_{2}$-supported samples. In fact, samples with Fe-loading higher than 8 wt $\%$ shows XRD patterns with characteristics peaks of hematite $\mathrm{Fe}_{2} \mathrm{O}_{3}$ (JCPDS: 33-0664). Thus, no iron oxide crystallites can be proposed for catalysts supported on $\mathrm{PCH}$; however, the presence of highly dispersed and/or amorphous phases cannot be ruled out.

As no iron oxides crystallites have been detected by XRD in several catalysts, Diffuse Reflectance UV-Vis spectra have been recorded on these catalysts in order to know more about the characteristics of the iron species. Figure 2 shows the DR-UV-Vis spectra of catalysts supported on $\mathrm{PCH}$ (Fig. 2a) and $\mathrm{SiO}_{2}$ (Fig. 2b). It is well known that tetrahedral $\mathrm{Fe}^{3+}$ species can be observed at $c a .215$ and $241 \mathrm{~nm}$ which can be attributed to two chargetransfer (CT) bands (associated to $\mathrm{t}_{1} \rightarrow \mathrm{t}_{1}$ and $\mathrm{t}_{1} \rightarrow \mathrm{e}$ transitions). In addition, octahedral $\mathrm{Fe}^{3+}$ species can be observed at ca. $278 \mathrm{~nm}$, whereas octahedral $\mathrm{Fe}^{3+}$ species in small clusters give rise to broad bands between 300 and $400 \mathrm{~nm}$. Finally, large $\mathrm{Fe}_{2} \mathrm{O}_{3}$ particle with low interaction with the support show a wide band at above $475 \mathrm{~nm}$ [24-26]. When the DR-UVvis spectra of $\mathrm{Fe} / \mathrm{PCH}$ and $\mathrm{Fe} / \mathrm{Si}$ series are compared important differences can be appreciated as remarkably broader spectra are observed in the catalysts based on conventional silica, and this means that the degree of aggregation of iron oxide is remarkably higher. In the case of the 
$\mathrm{Fe} / \mathrm{PCH}$ series (Figure 2a) similar spectra have been observed for all the iron loadings. Fe/Si series (Figure 2b) shows a wide band with some shoulders corresponding to iron oxide species with different degree of interaction with the support although the shape of the spectra varies depending on the Fe-loading. Thus, the catalyst with the lowest Fe-loading presents the lowest intensity for the iron oxide nanoparticles band. Accordingly, isolated FeOx and small clusters are the predominant species in the Fe/PCH series, whereas the presence of low aggregated $\mathrm{FeOx}$ and especially nanoparticles of iron oxide are notorious in the $\mathrm{Fe} / \mathrm{Si}$ series.

In order to identify possible differences in the spectral characteristics of these catalysts between ambient and reaction conditions, in-situ UV-Vis. experiments were recorded. In-situ conditions employed consisted of a flow of $50 \mathrm{ml} / \mathrm{min}$ with a gas composition of $1000 \mathrm{vppm}$ of toluene in synthetic air $\left(20 \% \mathrm{O}_{2}\right.$ in $\left.\mathrm{He}\right)$. The spectra were recorded from room temperature to $200^{\circ} \mathrm{C}$ using two representative catalysts $(8.5 \mathrm{Fe} / \mathrm{PCH}$ and $8.5 \mathrm{FeSi}$ catalysts) (Figure $\mathrm{S}-1$, Supplementary information). According to these results, no important differences regarding the intensity or preponderance of bands were observed at the different temperatures employed.

Figure 3 presents the TPR experiments for supported iron oxide catalysts. It can be observed important differences between those supported over PCH (Fig. 3a) and those supported on conventional silica (Fig. 3a). TPR profile of pure $\mathrm{Fe}_{2} \mathrm{O}_{3}$ is characterized by the presence of two peaks at around 400 and $600^{\circ} \mathrm{C}$, which are related to the reduction of $\mathrm{Fe}_{2} \mathrm{O}_{3}$ to $\mathrm{Fe}_{3} \mathrm{O}_{4}$ followed by the reduction of $\mathrm{Fe}_{3} \mathrm{O}_{4}$ to $\mathrm{Fe}$ [27]. However, in some cases it is observed three reduction peaks at ca. 325,400 and $625^{\circ} \mathrm{C}$ which can be related to the following reduction steps: i) $\mathrm{Fe}_{2} \mathrm{O}_{3}$ to $\mathrm{Fe}_{3} \mathrm{O}_{4}$; ii) $\mathrm{Fe}_{3} \mathrm{O}_{4}$ to $\mathrm{FeO}$; and iii) $\mathrm{FeO}$ to $\mathrm{Fe}$ [28]. The difference between both TPR profiles can be due to the different stabilization of $\mathrm{FeOx}$, as a consequence of the lower/higher interaction of Fe species with the metal oxide support [28, 29]. 
In our case, the TPR profiles of PCH-supported iron oxide show a reduction peak at ca. $330^{\circ} \mathrm{C}$ (in sample 4.4Fe/PCH) (Fig. 3a). A similar single peak has been also reported in iron oxide supported on MCM-41 [23], in which most of iron could be strongly interacting (or incorporated) with the mesoporous MCM-41. In addition to the peak at $330^{\circ} \mathrm{C}$, two new peaks at 500 and $630^{\circ} \mathrm{C}$ are also observed for $\mathrm{PCH}$-supported iron oxide samples with higher Feloading, suggesting the presence of highly dispersed $\mathrm{Fe}_{2} \mathrm{O}_{3}$ crystals with lower crystal size than those formed in $\mathrm{Fe} / \mathrm{Si}$ - series.

On the other hand, the silica-supported $\mathrm{Fe}_{2} \mathrm{O}_{3}$ catalysts are characterized by the presence of three peaks at $c a .300, c a .400$ and $c a .630{ }^{\circ} \mathrm{C}$ (Fig. 3b). Similar profiles have been observed for iron oxide supported on SBA-15 [20]. The intensity of the first reduction peak (related to highly dispersed Fe species) decreases when increasing the Fe-loading. However, the intensities of peaks at ca. 400 and ca. $630{ }^{\circ} \mathrm{C}$ (related to $\mathrm{Fe}_{2} \mathrm{O}_{3}$ crystallites) increase when increasing the Fe-loading. We must inform that the peaks at $c a .400$ and $c a .630{ }^{\circ} \mathrm{C}$ shift to higher temperatures when the Fe-loading increases as a consequence of the higher crystal size of iron oxide.

In order to determine the near surface composition of the catalysts, XPS analyses were carried out (Figure 4 and Table 2). Figure 4 shows that all Fe $2 p$ core level spectra display a similar pattern with binding energy values between 710.2 and $711.3 \mathrm{eV}$, which is attributed to the presence of $\mathrm{Fe}^{3+}$ species in the form of $\mathrm{Fe}_{2} \mathrm{O}_{3}$ or $\mathrm{FeOOH}$ [30]. It is noteworthy that the PCHsupported catalysts exhibit higher amount of Fe species on the catalyst surface in comparison to those supported on silica, suggesting a higher dispersion of the Fe species. These results are in agreement with the higher dispersion and smaller particle size proposed from DR-UVVis., TPR and XRD data.

With regard to the $\mathrm{O} 1 s$ core level spectra, all samples exhibit an asymmetric signal which can be decomposed into two contribution (Table S1): i) a main contribution, located about 532.9 
$\mathrm{eV}$, assigned to the oxygen species in the form of oxide coming from montmorillonite and silica pillars [31]; and ii) a second contribution, with lower intensity, which increases with the iron content, attributed to oxygen species bonded to iron [30].

The $\mathrm{Si} 2 \mathrm{p}$ core level spectra of catalysts supported on silica (Fe/Si series) and $\mathrm{PCH}(\mathrm{Fe} / \mathrm{PCH}$ series) show a single contribution located at ca. $103.5 \mathrm{eV}$, which is attributed to the presence of siliceous $\mathrm{Si}^{4+}$ species. On the other hand, the $\mathrm{Al} 2 p$ core level spectra of the Fe/PCH series show a contribution at $c a .74 .0 \mathrm{eV}$, which is related to the existence of aluminosilicate species coming from montmorillonite sheets [31]. Finally, it is noticeable the absence of contributions in the $\mathrm{Na} 1 \mathrm{~s}, \mathrm{Ca} 2 \mathrm{p}$ or $\mathrm{Mg} 2 \mathrm{p}$, which indicates a total substitution of the cations used to counterbalance the sheets $\left(\mathrm{Na}^{+}, \mathrm{Mg}^{2+}\right.$ or $\left.\mathrm{Ca}^{2+}\right)$ by $\mathrm{HDTM}^{+}$.

Figure 5 shows TEM images for representative supported iron oxide catalysts. The $8.5 \mathrm{FeSi}$ catalyst (Fig. 5, pictures a and b) consists of agglomerations of many silica nanoparticles particles, with size ranging from 10 to $25 \mathrm{~nm}$ and, over these particles, iron oxide dispersed or aggregated. Hematite $\mathrm{Fe}_{2} \mathrm{O}_{3}$ nanoparticles (NPs), mainly in the 5-10 nm range, without a welldefined shape, are located on silica particles. A few larger $\mathrm{Fe}_{2} \mathrm{O}_{3}$ particles of until $35 \mathrm{~nm}$ have also been observed. We must mention that according to the XRD analysis the hematite domains present a mean size of $12 \mathrm{~nm}$.

In the $8.5 \mathrm{FePCH}$ sample the porous characteristics of the PCH support is clearly seen and, over this structure, dispersed iron oxide is detected (Fig 5c). Moreover, small hematite crystallites, not bigger than $3 \mathrm{~nm}$, can be also observed (Fig 5d). The observation of these small crystallites is in agreement with the lack of large hematite iron oxide domains demonstrated by the absence of the corresponding reflection by XRD and also agrees with the absence (or low intensity) of the band assigned to bulk $\mathrm{Fe}_{2} \mathrm{O}_{3}$ particles in the DR-UV-Vis. spectra. 
Selected Area Electron Diffraction confirms the presence of Hematite $\mathrm{Fe}_{2} \mathrm{O}_{3}$ (JCPDS: 85-599) with space group R-3c in all the catalysts studied.

\subsection{Total oxidation of aromatics}

Iron oxide based catalysts were tested for the oxidation of 1000 ppmv of toluene. In all cases the only reaction product observed was $\mathrm{CO}_{2}$. Pure silica and the siliceous $\mathrm{PCH}$ were also tested, but none of them presented important conversion $(<3 \%$, which means an outlet toluene concentration higher than $970 \mathrm{ppm})$ at the highest temperature studied $\left(300^{\circ} \mathrm{C}\right)$.

Figure 6 shows the variation of the toluene conversion with the reaction temperatures for iron oxide catalysts supported on PCH (Fig. 6a) and on conventional silica (Fig. 6b). It can be clearly observed that the catalysts supported on siliceous PCH present remarkably higher catalytic activity than those supported on silica. Catalysts based on PCH show a similar profile than those on conventional silica but shifted $c a \cdot 75^{\circ} \mathrm{C}$ to lower temperatures. Thus, $50 \%$ conversion (500 ppmv of toluene remaining) is obtained using $\mathrm{PCH}$ as support at $c a$. $175^{\circ} \mathrm{C}$ whereas the same level of conversion is obtained at $c a .240^{\circ} \mathrm{C}$ using conventional silica. In the case of the most active catalyst, $15.6 \mathrm{Fe} / \mathrm{PCH}$, the conversion at a temperature as low as $188^{\circ} \mathrm{C}$ is $90 \%$, and this means an outlet toluene concentration of only $100 \mathrm{ppmv}$.

The catalytic activity cannot be properly compared between the catalysts supported on silica and on $\mathrm{PCH}$ as the activity in PCH based catalysts is at least two orders of magnitude higher than those based on silica. For both supports it has been observed that the catalytic activity per gram of catalyst increases with the iron loading. This fact together with the inactivity shown by pure supports indicates that active sites are only those of iron. If the catalytic activity is normalized per iron content, similar values can be seen in the Fe/PCH series. In the case of the Fe/Si series the catalyst with $4.4 \mathrm{wt} \%$ Fe presents the lowest specific activity and at $8.5-15.6 \mathrm{wt} \% \mathrm{Fe}$ similar values are obtained. 
For a comparative purpose, a commercial pure iron oxide (see experimental) was tested in toluene oxidation, showing a poor performance, worse than any of the supported catalysts. Thus, toluene conversion of $50 \%$ was achieved at $310^{\circ} \mathrm{C}$ (Table 1).

\subsection{Selective oxidation of $\mathrm{H}_{2} \mathrm{~S}$}

Iron oxide based catalysts were tested for the selective oxidation of $\mathrm{H}_{2} \mathrm{~S}$. The only reaction products observed were sulfur $(\mathrm{S})$ and sulfur dioxide $\left(\mathrm{SO}_{2}\right)$. Figure 7 presents the variation of $\mathrm{H}_{2} \mathrm{~S}$ conversion (Figure 7a) and the selectivity to sulfur (Figure $7 \mathrm{~b}$ ) with time on stream achieved during the partial oxidation of $\mathrm{H}_{2} \mathrm{~S}$ at $200^{\circ} \mathrm{C}$ on catalysts of $\mathrm{Fe} / \mathrm{PCH}$-series. The $\mathrm{H}_{2} \mathrm{~S}$ conversion increases when increasing the Fe-content. In addition, the catalysts also present significant catalyst decay during the first $350 \mathrm{~min}$, but then the catalytic activity is stabilized. On the other hand, the selectivity to sulfur seems to be stabilized during all the experiment, since no apparent changes in selectivity are observed with the time on line for the three catalysts studied. However, the selectivity to sulfur depends on the iron loading and a slight decrease is observed when the amount of Fe increases.

Figure 8 presents the variation of $\mathrm{H}_{2} \mathrm{~S}$ conversion (Figure 8a) and the selectivity to sulfur (Figure 8b) with time of stream achieved during the partial oxidation of $\mathrm{H}_{2} \mathrm{~S}$ at $200^{\circ} \mathrm{C}$ on catalysts of $\mathrm{Fe} / \mathrm{Si}$-series. The $\mathrm{H}_{2} \mathrm{~S}$ conversion increases when increasing the Fe-loading. However, in all cases it is also observed an initial catalyst decay, followed by stabilization after ca. 350 min. In this way, the selectivity to sulfur decreases when Fe-loading increases. In addition, the selectivity to sulfur decreases also with time on stream. Thus, changes in the catalyst must be taking place during the reaction as the catalysts show lower activity and selectivity at the end of the experiment.

When comparing the catalytic performance of $\mathrm{Fe} / \mathrm{PCH}$ and $\mathrm{Fe} / \mathrm{Si}$ catalysts, it can be concluded that $\mathrm{Fe} / \mathrm{PCH}$ catalysts are more active and more selective to the formation of 
sulphur (partial oxidation) than the corresponding Fe/Si catalysts. In this way, Fe/Si catalysts favour a higher formation of undesirable $\mathrm{SO}_{2}$ (by combustion of $\mathrm{H}_{2} \mathrm{~S}$ and $\mathrm{S}$ ).

\subsection{Relationship between catalytic and characterization results}

In the present article, iron oxide has been impregnated on two different siliceous supports. In FeOx catalysts supported on siliceous porous clay heterostructure the iron oxide species have been efficiently dispersed on the surface as no iron containing phases have been detected by XRD and highly dispersed FeOx species can be inferred from DR-UV-Vis. spectra. The absence of diffractions of $\mathrm{Fe}_{2} \mathrm{O}_{3}$ indicates that $\mathrm{Fe}_{2} \mathrm{O}_{3}$ crystallites, if present, have low size. This fact is in agreement with the XPS data where the higher proportion of iron species located on the surface of the catalysts supported on $\mathrm{PCH}$ suggests the presence of small particles well dispersed on the surface of the catalyst (see Table 2). Accordingly, TEM results suggest the presence of a few tiny $\mathrm{Fe}_{2} \mathrm{O}_{3}$ crystallites. Thus in the case of $\mathrm{Fe} / \mathrm{PCH}$ series $\mathrm{FeOx}$ species are mainly isolated or present with low aggregation. In contrast, nanoparticles of $\mathrm{Fe}_{2} \mathrm{O}_{3}$ are abundant if the support is conventional silica as observed by XRD and confirmed by the DR-UV-Vis. data, especially in those catalysts with 8 wt.\% Fe and higher. Moreover, the TEM studies confirm the presence of 5-15 nm hematite $\mathrm{Fe}_{2} \mathrm{O}_{3}$ nanoparticles.

Catalytic activity for the two reaction tested (toluene oxidation and selective oxidation of $\mathrm{H}_{2} \mathrm{~S}$ ) has been shown to be highly dependent on the nature of the FeOx species and can be clearly correlated with the characterization results. Thus, it is observed that highly dispersed FeOx species over the support present the highest catalytic activity, considerably higher than that of iron oxides crystallites. TPR profiles present important differences depending on the support employed; however the onset temperature $\left(c a \cdot 170^{\circ} \mathrm{C}\right)$ and the temperature for the maximum hydrogen consumption $\left(\mathrm{ca} .320^{\circ} \mathrm{C}\right)$ is similar for all the catalysts tested regardless of the iron oxide loading and of the nature of the support. Therefore, reducibility determined 
by TPR cannot explain the different catalytic activity and consequently a correlation with the catalytic activity cannot be appreciated. The higher activity observed by dispersed $\mathrm{FeOx}$ species in toluene oxidation is in agreement with the work of Zhang et al. [13] in which using Fe/SBA-15 catalysts observed that dispersed iron oxide was more active than aggregated FeOx species. However, in that article the most dispersed species presented a higher reducibility, in contrast with the observations of the present work.

The effect of the iron loading of the catalysts on the toluene oxidation is clear for both supports, since catalytic activity per mass of catalyst increases with the Fe-content. In fact, the T50 (reaction temperature required to achieve $50 \%$ conversion) decreases $20-25^{\circ} \mathrm{C}$ between the catalysts with the lowest iron loading and those with the highest loading. However, if only the iron sites are considered to determine the catalytic activity, similar values were observed in the Fe/PCH series. Moreover, catalysts of the Fe/Si series with $8.5-15.6 w t \%$ Fe present similar catalytic activity per mass of iron (although remarkably lower than those of the $\mathrm{Fe} / \mathrm{PCH}$ series).

The fact that for iron oxide supported catalysts the presence of dispersed FeOx species leads to the highest catalytic activity in the toluene oxidation contrasts with the trend observed in supported cobalt oxide catalysts, which is probably the most active metal oxide not based on noble metals for the total oxidation of VOCs. If cobalt oxide is well dispersed on the support, strong Co-O-support bonds with low reducibility are formed [32] and, consequently, low catalytic activity is obtained.

The high catalytic activity in the $\mathrm{H}_{2} \mathrm{~S}$ oxidation observed using the iron catalysts supported on the porous structure $(\mathrm{PCH})$ is likely due to the high iron oxide dispersion achieved, which is higher than the dispersion observed if silica is used as a support. This fact has been corroborated by several physicochemical techniques. Therefore, the amount of available iron 
oxide sites is higher using the porous structure as a support than using silica and consequently the catalytic activity is also higher.

The stability of representative iron oxide catalysts was studied for both catalytic reactions. The evolution of the toluene conversion of $8.5-\mathrm{Fe} / \mathrm{PCH}$ sample has been plotted with the time on line. Thus at a reaction temperature of $180^{\circ} \mathrm{C}$ it has been observed an unmodified toluene conversion of $60-65 \%$ for $12 \mathrm{~h}$ (Supplementary information, Fig. S-2). This stability is likely related to the scarce modifications of the catalysts during the reaction; if the used catalyst is compared to the fresh catalyst no appreciable differences can be observed as demonstrated by XRD, DR-UV-Vis, and XPS. A further stability test was performed in toluene oxidation using 8.5-Fe/PCH catalyst. Thus, 12 cycles were conducted using the same temperature ramp than in Figure 6. Once $100 \%$ conversion was achieved at $225^{\circ} \mathrm{C}$, the furnace was switched off and the feed was maintained. The reactor was cooled down until $50^{\circ} \mathrm{C}$ and then a subsequent cycle was undertaken. The stability observed was excellent without important deviations compared to the first cycle (Fig. S-3, Supplementary information).

As mentioned above, in the oxidation of $\mathrm{H}_{2} \mathrm{~S}$ the performance of the catalysts was studied with the time on line. For example, in the case of $15.6-\mathrm{Fe} / \mathrm{PCH}$ catalyst it has been observed a catalyst decay during the first $300 \mathrm{~min}$, and then a rather stable period, with a yield of sulfur of ca. 70\%; for $2 \mathrm{~h}$ (Fig. S-4, Supplementary information). This behaviour is similar to those reported on other supported $\mathrm{Fe}_{2} \mathrm{O}_{3}$ based catalysts $[19,20,33]$. We must indicate that several interpretations on the causes of the catalyst decay have been proposed in the last years. Thus, Zhang et al. [19b] proposed that the presence of little elemental sulfur (due to the relatively low reaction temperature, i.e. sulfur dew point), causes catalyst deactivation when using iron oxide supported over laponite. However, in the case of $\mathrm{Fe}_{2} \mathrm{O}_{3} / \mathrm{SBA}-15$ catalysts, it has been proposed that the presence of sulfates, in addition to changes in the Fe environment, has a role in the slight deactivation observed using these catalysts [20]. On the other hand, it has been 
suggested that iron oxide selectively catalyses the partial oxidation of $\mathrm{H}_{2} \mathrm{~S}$ to sulfur, whereas $\mathrm{H}_{2} \mathrm{~S}$ combustion (with the formation of $\mathrm{SO}_{2}$ ) is governed by $\mathrm{FeS}_{2}$ [34]. In the present work we have not observed the presence of $\mathrm{FeS}_{2}$ by XRD in the used catalysts (Fig. S-5, Supplementary information) and therefore we cannot confirm the role of $\mathrm{FeS}_{2}$ in the $\mathrm{SO}_{2}$ formation.

The XPS data of the Fe/PCH catalysts used after $\mathrm{H}_{2} \mathrm{~S}$ oxidation show the same $\mathrm{Fe}$ and $\mathrm{Si}$ contributions with very similar binding energy, which suggests that FeOx species are stable and do not evolve to other crystallographic phase during the selective oxidation of $\mathrm{H}_{2} \mathrm{~S}$. In addition, the $S 2 p$ core level spectra show the emergence of a new signal that can be decomposed into two signals; the first one located about $163.8 \mathrm{eV}$ and the second one located at $c a .169 .2 \mathrm{eV}$, which are ascribed to the presence of sulfur in the form of elementary sulfur and sulfate species, respectively [30]. From the XPS data, it can be inferred that sulfide species are not strongly bound to the phase $\mathrm{FeOx}$, while the obtained products, i.e. elementary sulfur and sulfate, are retained on the surface of the catalyst (Figure 9). The strong interaction between the active phase and products causes a decrease of the available active sites probably being the responsible for the deactivation of the catalysts along the time on stream. This fact is in agreement with the data shown in the atomic concentration where $\mathrm{Fe} /(\mathrm{Si}+\mathrm{Al})$ decreases due to the deposition of sulfur species on the surface of the active phase. As can be seen in Figure 9 and Table 3 the amount of S-species in Fe/PCH and Fe/Si catalysts increase with the amount of iron in the catalysts. Interestingly, it is observed that the $\mathrm{S} / \mathrm{Fe}$ ratio also increases with the iron loading. However, there are not substantial differences between the two supports suggesting that the $\mathrm{S}$ retention depends more on the iron loading than on the dispersion of the iron species. Therefore, the amount of S detected on the surface does not seem to be related to the drop in the catalytic activity. 
In the case of the most active catalysts of both series (i.e. samples with $15.6 \% \mathrm{Fe}$ ) the $\mathrm{S}$ loading as well as the $\mathrm{S} / \mathrm{Fe}$ ratio is lower in the catalyst supported on silica than on the porous support. High S content on the surface after use can be related to the ease of the active sites to form S-containing products ( $\mathrm{S}$ and $\mathrm{SO}_{2}$ ) and consequently to the catalytic activity. However, high S-loadings can be also related to the deactivation, since S (in the form of sulfates or elemental sulfur) blocks the surface active sites. Therefore, a relationship between $\mathrm{S} / \mathrm{Fe}$ and catalytic activity is not straightforward to establish.

Interestingly, it can be observed that the relative amount of sulfate and sulfur species on the surface also depends on the iron loading. Thus, the amount of sulfate species is remarkably higher in the Fe/PCH catalyst with the highest Fe-loading (sulfate/sulfur = 3.7) than in the catalyst with the lowest Fe-loading (sulfate/sulfur $=0.95$ ). As sulfate species are intermediates for the $\mathrm{SO}_{2}$ formation this observation matches with the lower selectivity to elemental $\mathrm{S}$ (and consequently the higher selectivity to $\mathrm{SO}_{2}$ ) obtained during the hydrogen sulphide oxidation experiments with the high Fe-loading sample. Additionally, if $\mathrm{Fe} / \mathrm{PCH}$ and $\mathrm{Fe} / \mathrm{Si}$ catalysts are compared, higher proportion of sulfate species is observed in $\mathrm{Fe} / \mathrm{Si}$ catalysts. The major detection of surface sulfate species is in agreement with the higher production of $\mathrm{SO}_{2}$. This can be the responsible for the lower selectivity to $\mathrm{S}$ observed in Fe/Si catalysts and maybe also for the higher drop in catalytic activity.

As a summary, the highly dispersed nature of the iron species on the porous clay heterostructure leads to high catalytic activity in the total oxidation of toluene and this is probably due to the higher amount of available sites because of the higher dispersion of the iron species. We cannot relate this higher activity to an enhanced reducibility as no clear relationship is observed in the TPR experiments. In fact, a non redox Rideal-Eley mechanism has been proposed in the toluene oxidation on Fe catalysts [15]. 
In the case of the $\mathrm{H}_{2} \mathrm{~S}$ oxidation the use of the pillared clay heterostructures instead of conventional silica as a support of iron oxide also leads to higher catalytic activity. Moreover the use of PCH as supports leads to higher selectivity to elementary S and lower deactivation. The higher selectivity to elementary $\mathrm{S}$ is likely due to the predominance of isolated and low aggregated species, which are more selective to $\mathrm{S}$ than $\mathrm{Fe}_{2} \mathrm{O}_{3}$ crystallites. The lower deactivation does not seem to be due to the lower amount of $S$ adsorbed on the surface of the catalysts but is maybe related to the lower amount of surface sulfate species detected.

\section{Conclusions}

Porous Clays Heterostructures (PCH) are efficient supports of iron oxide for environmental catalysis. These catalysts have been tested in both the i) total oxidation of toluene and ii) the selective oxidation of $\mathrm{H}_{2} \mathrm{~S}$ to elemental sulfur. In the total oxidation of a representative VOC (toluene) high catalytic activity has been observed with iron oxide supported on siliceous $\mathrm{PCH}$, at least two orders of magnitude higher than those results obtained by pure iron oxide bulk or iron oxide supported on conventional silica. The higher activity has been related to the presence of highly isolated $\mathrm{FeOx}$ species, which are more reactive than more aggregated FeOx species and $\mathrm{Fe}_{2} \mathrm{O}_{3}$ crystallites. In the case of the selective oxidation of $\mathrm{H}_{2} \mathrm{~S}$ to $\mathrm{S}$ higher catalytic activity, higher selectivity to $\mathrm{S}$ (and lower $\mathrm{SO}_{2}$ formation) and better stability has been observed using porous clays heterostructures as supports for iron oxide than using iron oxide supported on silica. The presence of highly dispersed FeOx species has been linked to the highest catalytic activity as, this way, more active iron sites are available. In the case of the product distribution, $\mathrm{Fe} / \mathrm{PCH}$ catalysts present higher selectivity to elemental $\mathrm{S}$, and this is in agreement with the lower formation on the surface of adsorbed sulfates which are intermediates for $\mathrm{SO}_{2}$ formation. The lower drop in $\mathrm{H}_{2} \mathrm{~S}$ conversion could be related to the 
lower concentration of surface sulfate species detected but not to the overall amount of $S$ adsorbed.

\section{Acknowledgments}

The authors would like to acknowledge the DGICYT in Spain (CTQ2015-68951-C3-1-R, CTQ2015-68951-C3-3-R, CTQ2012-37925-C03-2, CTQ2012-37925-C03-3 and CTQ201237984-C02-01) and FEDER for financial support. We also thank the University of Valencia for funding (UV-INV-AE-16-484416) and SCSIE-UV for assistance. 


\section{References}

1. T. García, B. Solsona, S.H. Taylor, The Catalytic Oxidation of Hydrocarbon Volatile Organic Compounds, in D. Duprez and F. Cavani (Eds.), Handbook of Advanced Methods and Processes in Oxidation Catalysis, Imperial College Press, London, 2014, pp $51-90$.

2. K. Everaert, J. Baeyens, The Catalytic Oxidation of Hydrocarbon Volatile Organic Compounds. J. Hazard. Mater. B 109 (2004) 113-139.

3. P. Gelin, M. Primet, Complete Oxidation of methane at low temperature over noble metal based catalysts: a review, Appl. Catal. B: Environ. 39 (2002) 1-37.

4. J. J. Spivey, Complete catalytic oxidation of volatile organics Ind. Eng. Chem. Res. 26 (1987) 2165-2180.

5. Y. Du, Q. Meng, J. Wang, J. Yan, H. Fan, Y. Liu, H. Dai, Three-dimensional mesoporous manganese oxides and cobalt oxides: High-efficiency catalysts for the removal of toluene and carbon monoxide, Microp. Mesop. Mater. 162 (2012) 199-206.

6. S.A.C. Carabineiro, X. Chen, M. Konsolakis, A.C. Psarras, P.B. Tavares, J.J.M. Órfão, M.F.R. Pereira, J.L. Figueiredo, Catalytic oxidation of toluene on Ce-Co and La-Co mixed oxides synthesized by exotemplating and evaporation methods, Catal. Today 244 (2015) $161-171$.

7. Qingyun Yan, Xinyong Li, Qidong Zhao, Guohua Chen, Shape-controlled fabrication of the porous $\mathrm{Co}_{3} \mathrm{O}_{4}$ nanoflower clusters for efficient catalytic oxidation of gaseous toluene J. Hazard. Mater. 209- 210 (2012) 385-391

8. W. Si, Y. Wang, Y. Peng, X. Li, K. Li, J. Li, A high-efficiency c-MnO 2 -like catalyst in toluene Combustion, Chem. Commun. 51 (2015) 14977-14980. 
9. M. Piumetti, D. Fino, N. Russo, Mesoporous manganese oxides prepared by solution combustion synthesis as catalysts for the total oxidation of VOCs, Appl. Catal. B: Environ. 163 (2015) 277-287.

10. W.B. Li, J.X. Wang, H. Gong, Catalytic combustion of VOCs on non-noble metal catalysts, Catal. Today, 148 (2009) 81-87.

11. A.L. Barbosa, J. Herguido, J. Santamaría, Methane combustion over unsupported iron oxide catalysts, Catal. Today 64 (2001) 43-50.

12. V.A. Sazonov, Z.R. Ismagilov, N.A. Prokudina, Catalytic combustion of lean methane \pm air mixtures, Catal. Today 47 (1999) 149-153.

13. a) Y. Zhang, J. Deng, L. Zhang, H. Dai, Preparation and catalytic performance of FeSBA-15 and FeOx/SBA-15 for toluene combustion, Chin. Sci. Bull. 59 (2014) 39934002; b) B. Solsona, T. García, R. Sanchis, M.D. Soriano, M. Moreno, E. RodríguezCastellón, S. Agouram, A. Dejoz, J.M. López Nieto, Total oxidation of VOCs on mesoporous iron oxide catalysts: Soft chemistry route versus hard template method, Chem. Eng. J., 290 (2016) 273-281.

14. a) M. Baldi, V. Sánchez-Escribano, J.M. Gallardo Amores, F. Milella, G. Busca, Characterization of manganese and iron oxides as combustion catalysts for propane and propene, Appl. Catal. B: Environ. 17 (1998) L175-L182.; b) T. Kobayashi, N. Guilhaume, J. Miki, N. Kitamura, M. Haruta, Oxidation of methane to formaldehyde over $\mathrm{Fe} / \mathrm{SiO}_{2}$ and Sn-W mixed oxides, Catal. Today 32 (1996) 171-175.

15. F. G. Duran, B. P. Barbero, L. E. Cadus, C. Rojas, M. A. Centeno, J. A. Odriozola, Manganese and iron oxides as combustion catalysts of volatile organic compounds, Appl. Catal. B: Environ. 92 (2009) 194-201.

16. X. Zhang, Y. Tang, S. Qu, $\mathrm{H}_{2} \mathrm{~S}$-Selective Catalytic Oxidation: Catalysts and Processes, ACS Catalysis 5 (2015) 1053-1067. 
17. a) P.J. van den Brink, R.J.A.M Terörde, J.H. Moors, A.J. van Dillen, J.W. Geus, Selective oxidation of hydrogen sulfide to elemental sulfur on supported iron sulfate catalysts, Stud. Surf. Sci. Cat. 72 (1992) 123-132; b) S. Yasyerli, Cerium-manganese mixed oxides for high temperature $\mathrm{H}_{2} \mathrm{~S}$ removal and activity comparisons with $\mathrm{V}-\mathrm{Mn}$, Zn-Mn, Fe-Mn sorbents, Chem. Eng. Process 47 (2008) 577-584; c) R.J.A.M. Terörde, P.J. van den Brink, L.M. Visser, A.J. van Dillen, Selective oxidation of hydrogen sulfide to elemental sulfur using iron oxide catalysts on various supports, Catal. Today 17 (1993) 217-224.

18. a) K.J. Cantrell, S.B. Yabusaki, M.H. Engelhard, A.V. Mitroshkov, E.C. Thornton, Oxidation of $\mathrm{H}_{2} \mathrm{~S}$ by Iron Oxides in Unsaturated Conditions, Environ. Sci. Technol. 37 (2003) 2192-2199; b) B.S. Liu, X.N. Wei, Y.P. Zhan, R.Z. Chang, F. Subhan, C.T. Au, Preparation and desulfurization performance of LaMeOx/SBA-15 for hot coal gas, Appl. Catal. B: Environ. 102 (2011) 27-36.

19. a) X. Wang, J. Jia, L. Zhao, T. Sun, Mesoporous SBA-15 Supported Iron Oxide: A Potent Catalyst for Hydrogen Sulfide Removal, Water Air Soil Poll. 193 (2008) 247-257; b) X. Zhang, G. Dou, Z. Wang, L. Li, Y. Wang, H. Wang, Z. Hao, Selective catalytic oxidation of $\mathrm{H} 2 \mathrm{~S}$ over iron oxide supported on alumina-intercalated Laponite clay catalysts, J. Hazard. Mater. 260 (2013) 104-111.

20. A. Reyes-Carmona, M.D. Soriano, J.M. Lopez Nieto, D.J. Jones, J. Jiménez-Jiménez, A. Jiménez-López, E. Rodríguez-Castellón, Iron-containing SBA-15 as catalyst for partial oxidation of hydrogen sulfide, Catal. Today 210 (2013) 117-123.

21. A. Vaccari, Clays and catalysis: a promising future, Appl. Clay Sci. 14 (1999) 161-198.

22. J.A. Cecilia, C. García-Sancho, F. Franco, Montmorillonite based porous clay heterostructures: Influence of $\mathrm{Zr}$ in the structure and acidic properties, Micropor. Mesopor. Mater. 176 (2013) 95-102. 
23. P. Mohapatra, T. Mishra, K.M. Parida, Pillared clay as an effective catalyst for low temperature VOCs decomposition, Key Eng. Mater. 571 (2013) 71-91.

24. L. Luo, Ch.i Dai, A. Zhang, J. Wang,. Ch. Song, X. Guo, Evolution of iron species for promoting the catalytic performance of FeZSM-5 in phenol oxidation, RSC Adv. 6 (2016) 32789-32797.

25. A. Gervasini, Cl. Messi, A. Ponti, S. Cenedese, N. Ravasio, Nanodispersed Fe Oxide Supported Catalysts with Tuned Properties, J. Phys. Chem. C 2008, 112,4635-4642.

26. F. Arena, G. Gatti, G. Martra, S. Coluccia, L. Stivano, L. Spadaio, P. Famulari, A. Parmaliana, Structure and reactivity in the selective oxidation of methane to formaldehyde of low-loaded $\mathrm{FeOx} / \mathrm{SiO}_{2}$ catalysts, J. Catal. 231 (2005) 365-380.

27. J.A. Pena, E. Lorente, E. Romero, J. Herguido, Kinetic study of the redox process for storing hydrogen Reduction stage, Catal. Today 116 (2006) 439-444.

28. a) K. Park, J.H. Jung, H. Seo, O. Kwon, Mesoporous silica-pillared kenyaite and magadite as catalytic support for partial oxidation of methane, Microp. Mesop. Mat. 121, 219-225; b) F.G.E. Nogueira, J.H. Lopes, A.C. Silva, R.M. Lago, J.D. Fabris, L.C.A. Oliveira, Catalysts based on clay and iron oxide for oxidation of toluene, Appl. Clay Sci. 51 (2011) 385-389; c) H. Hayashi, M. Kishida, K. Wakabayashi, Metal-Support Interaction and Catalysis of the Catalysts Prepared Using Microemulsion, Catal. Surv. Jpn. 6 (2002) 9-17.

29. S.A.C. Carabineiro, N. Bogdanchikova, P.B. Tavares, J.L. Figueiredo, Nanostructured iron oxide catalysts with gold for the oxidation of carbon monoxide, RSC Adv. 2 (2012) 2957-2965.

30. J.F. Moulder, W.F. Stickle, P.E. Sobol, K.D. Bomben, Handbook of X-ray Photoelectron Spectroscopy, Perkin-Elmer Corp, Eden Prairie, MN, 1992. 
31. R.M. Alves-Saboya, J.A. Cecilia, C. García-Sancho, F.M.T. Luna, E. RodríguezCastellón, C.L. Cavalcante Jr., $\mathrm{WO}_{3}$-based catalysts supported on porous clay heterostructures $(\mathrm{PCH})$ with $\mathrm{Si}-\mathrm{Zr}$ pillars for synthetic esters production, Appl. Clay Sci. $124-125$ (2016) 69-78.

32. B. Solsona, T.E. Davies, T. García, M.I. Vázquez, A. Dejoz, S.H. Taylor, Total oxidation of propane using nanocrystalline cobalt oxide and supported cobalt oxide catalysts, Appl. Catal., B: Environ., 84 (2008) 176-184.

33. N. Keller, C. Pham-Huu, M.J. Ledoux, Continuous process for selective oxidation of $\mathrm{H}_{2} \mathrm{~S}$ over SiC-supported iron catalysts into elemental sulfur above its dewpoint, Appl. Catal. A: Gen 217 (2001) 205-217.

34. N.K. Sakaeva, V.A Varnek, G.A Bukhtiyarova, V.F. Anufrienko, E.A Sobolev, B.P. Zolotovski, Mösbauer Spectroscopy study of alumina-supported iron containing catalysts for hydrogen sulphide oxidation, React. Kinet. Catal. Lett. 70 (2000) 169-176. 
Table 1. Physico-chemical and catalytic characteristics of iron containing catalysts.

\begin{tabular}{|c|c|c|c|c|c|c|c|}
\hline \multirow[t]{2}{*}{ Catalyst } & \multirow{2}{*}{$\begin{array}{l}\mathrm{Fe} \\
\text { (wt.\%) }\end{array}$} & \multirow{2}{*}{$\begin{array}{l}\mathrm{S}_{\mathrm{BET}} \\
\left(\mathrm{m}^{2} \mathrm{~g}^{-1}\right)\end{array}$} & \multicolumn{3}{|c|}{ Catalytic activity toluene $^{a}$} & \multicolumn{2}{|l|}{ TPR results ${ }^{e}$} \\
\hline & & & $\mathrm{T}_{50}\left({ }^{\circ} \mathrm{C}\right)^{\mathrm{b}}$ & per $\mathrm{kg}$ of catalyst $^{\mathrm{c}}$ & per $\mathrm{kg}$ of iron $^{\mathrm{d}}$ & $\begin{array}{l}\mathrm{H}_{2} \text {-uptake } \\
\left(\mathrm{mmol} \mathrm{g}^{-1}\right)\end{array}$ & $\begin{array}{l}\mathrm{T}_{\mathrm{MP}} \\
\left({ }^{\circ} \mathrm{C}\right)\end{array}$ \\
\hline 4.4-Fe/PCH & 4.4 & 474 & 195 & 2.05 & 45.9 & 0.80 & 331 \\
\hline 8.5-Fe/PCH & 8.5 & 434 & 180 & 5.39 & 63.1 & 1.18 & 331 \\
\hline 15.6-Fe/PCH & 15.6 & 394 & 170 & 8.42 & 54.0 & 1.84 & 335 \\
\hline 4.4-Fe/Si & 4.4 & 169 & 250 & $<0.1(1.01)$ & $1(22.9)$ & 0.71 & 315 \\
\hline 8.5-Fe/Si & 8.5 & 171 & 240 & $<0.1(3.7)$ & $1(43.4)$ & 1.95 & 318 \\
\hline 15.6-Fe/Si & 15.6 & 150 & 225 & $<0.1(9.1)$ & $<1(58.3)$ & 2.51 & 311 \\
\hline $\mathrm{Fe}$ & $70^{\mathrm{f}}$ & 3.3 & 310 & $<0.1(<0.1)$ & - & - & - \\
\hline
\end{tabular}

a) Determined at $160^{\circ} \mathrm{C}$ or, in parenthesis, at $210^{\circ} \mathrm{C}$ (additional experiments were conducted at these temperatures); b) Reaction temperature for toluene conversion of $50 \%$; c) expressed as $\mathrm{g}_{\text {toluene }} \mathrm{kg}_{\mathrm{cat}}{ }^{-1} \mathrm{~h}^{-1}$; d) expressed as $\mathrm{g}_{\text {toluene }} \mathrm{kg}_{\mathrm{Fe}}{ }^{-1} \mathrm{~h}^{-1}$; e) TPR-H $\mathrm{H}_{2}$ experiments undertaken until $\left.800^{\circ} \mathrm{C} ; \mathbf{f}\right)$ pure iron oxide $\mathrm{Fe}_{2} \mathrm{O}_{3}$. 
Table 2. Chemical composition (at. \%) of the near surface determined by XPS of Fe/PCH and Fe/Si catalysts (fresh and used in $\mathrm{H}_{2} \mathrm{~S}$ oxidation).

\begin{tabular}{|c|c|c|c|c|c|c|}
\hline Sample & $\mathrm{C}$ & $\mathrm{O}$ & $\mathrm{Al}$ & $\mathrm{Si}$ & $\mathrm{Fe}$ & $\mathrm{Fe} /(\mathrm{Si}+\mathrm{Al}), \%$ \\
\hline 4.4-Fe/PCH & 9.72 & 60.76 & 1.85 & 27.40 & 0.27 & 0.92 \\
\hline 4.4-Fe/PCH used & 4.54 & 66.01 & 2.01 & 26.84 & 0.18 & 0.62 \\
\hline 8.5-Fe/PCH & 10.24 & 60.26 & 1.79 & 27.23 & 0.48 & 1.65 \\
\hline 8.5-Fe/PCH used & 4.08 & 65.20 & 2.16 & 27.01 & 0.36 & 1.23 \\
\hline 15.6-Fe/PCH & 9.44 & 61.97 & 1.89 & 25.46 & 1.24 & 4.53 \\
\hline 15.6-Fe/PCH used & 4.84 & 63.66 & 2.30 & 26.36 & 0.70 & 2.44 \\
\hline 4.4-Fe/Si & 3.89 & 62.98 & - & 32.96 & 0.18 & 0.55 \\
\hline 4.4-Fe/Si used & 3.39 & 65.28 & - & 30.90 & 0.15 & 0.48 \\
\hline 8.5-Fe/Si & 3.92 & 63.42 & & 32.45 & 0.21 & 0.65 \\
\hline 8.5-Fe/Si used & 1.81 & 66.61 & & 30.49 & 0.24 & 0.78 \\
\hline 15.6-Fe/Si & 6.01 & 61.63 & & 31.76 & 0.60 & 1.89 \\
\hline 15.6-Fe/Si used & 3.42 & 64.06 & - & 29.89 & 0.74 & 2.42 \\
\hline
\end{tabular}


Table 3. Sulfur (at.) of the near surface determined by XPS of $\mathrm{Fe} / \mathrm{PCH}$ and $\mathrm{Fe} / \mathrm{Si}$ catalysts used in $\mathrm{H}_{2} \mathrm{~S}$ oxidation.

\begin{tabular}{ccccc}
\hline Sample & $\mathrm{S}($ at.\%) & $\mathrm{S} / \mathrm{Fe}$ & $\mathrm{S} /(\mathrm{Si}+\mathrm{Al}), \%$ & Sulfate $_{169.2 \mathrm{ev}} /$ Sulfur $_{163.8 \mathrm{eV}}$ \\
\hline 4.4-Fe/PCH used & 0.39 & 2.16 & 1.35 & 0.95 \\
8.5-Fe/PCH used & 0.96 & 2.67 & 3.29 & 2.9 \\
15.6-Fe/PCH used & 2.13 & 3.04 & 7.43 & 3.7 \\
\hline 4.4-Fe/Si used & 0.29 & 1.93 & 0.94 & 4.2 \\
8.5-Fe/Si used & 0.78 & 3.25 & 2.56 & 4.7 \\
15.6-Fe/Si used & 1.89 & 2.55 & 6.32 & 5.5 \\
\hline
\end{tabular}




\section{Caption to Figure}

Fig. 1. XRD patterns of $\mathrm{xFe} / \mathrm{PCH}$ and $\mathrm{xFe} / \mathrm{Si}$ catalysts.

Fig. 2. Diffuse reflectance UV-vis spectra of $\mathrm{xFe} / \mathrm{PCH}$ (a) and $\mathrm{xFe} / \mathrm{Si}$ (b) catalysts.

Fig. 3. TPR- $\mathrm{H}_{2}$ profiles of $\mathrm{xFe} / \mathrm{PCH}$ (a) and $\mathrm{xFe} / \mathrm{Si}$ (b) catalysts.

Fig. 4. Fe $2 p$ core level spectra of A) iron oxide supported on a conventional amorphous silica and on the porous clay heterostructure $(\mathrm{PCH})$ and $\mathrm{B}$ ) iron oxides supported on PCH before and after use in $\mathrm{H}_{2} \mathrm{~S}$ oxidation (reaction conditions in text).

Fig.5. TEM study of 8.5FeSi catalyst (a TEM image, b bright field scan) and 8.5FePCH (c TEM image, d High Resolution TEM image).

Fig.6. Variation of toluene conversion with reaction temperature achieved during the combustion of toluene over $\mathrm{xFe} / \mathrm{PCH}$ (a) or $\mathrm{xFe} / \mathrm{Si}$ (b) catalysts. Reaction conditions in text.

Fig. 7. Variation of $\mathrm{H}_{2} \mathrm{~S}$ conversion (a) and selectivity to sulfur (b) with time on stream achieved during the partial oxidation of $\mathrm{H}_{2} \mathrm{~S}$ over xFe/PCH catalysts. Reaction conditions in text, $\left(\mathrm{W} / \mathrm{F}=32.6 \mathrm{~g}_{\mathrm{cat}} \mathrm{h} \mathrm{mol}^{-1}\right)$.

Fig. 8. Variation of $\mathrm{H}_{2} \mathrm{~S}$ conversion (a) and selectivity to sulfur (b) with time on stream achieved during the partial oxidation of $\mathrm{H}_{2} \mathrm{~S}$ over $\mathrm{xFe} / \mathrm{Si}$ catalysts. Reaction conditions in text, $\left(\mathrm{W} / \mathrm{F}=65.2 \mathrm{~g}_{\mathrm{cat}} \mathrm{h} \mathrm{mol}{ }^{-1}\right)$. 
Fig. 9. S 2p core level spectra of iron oxide catalysts supported on PCH.

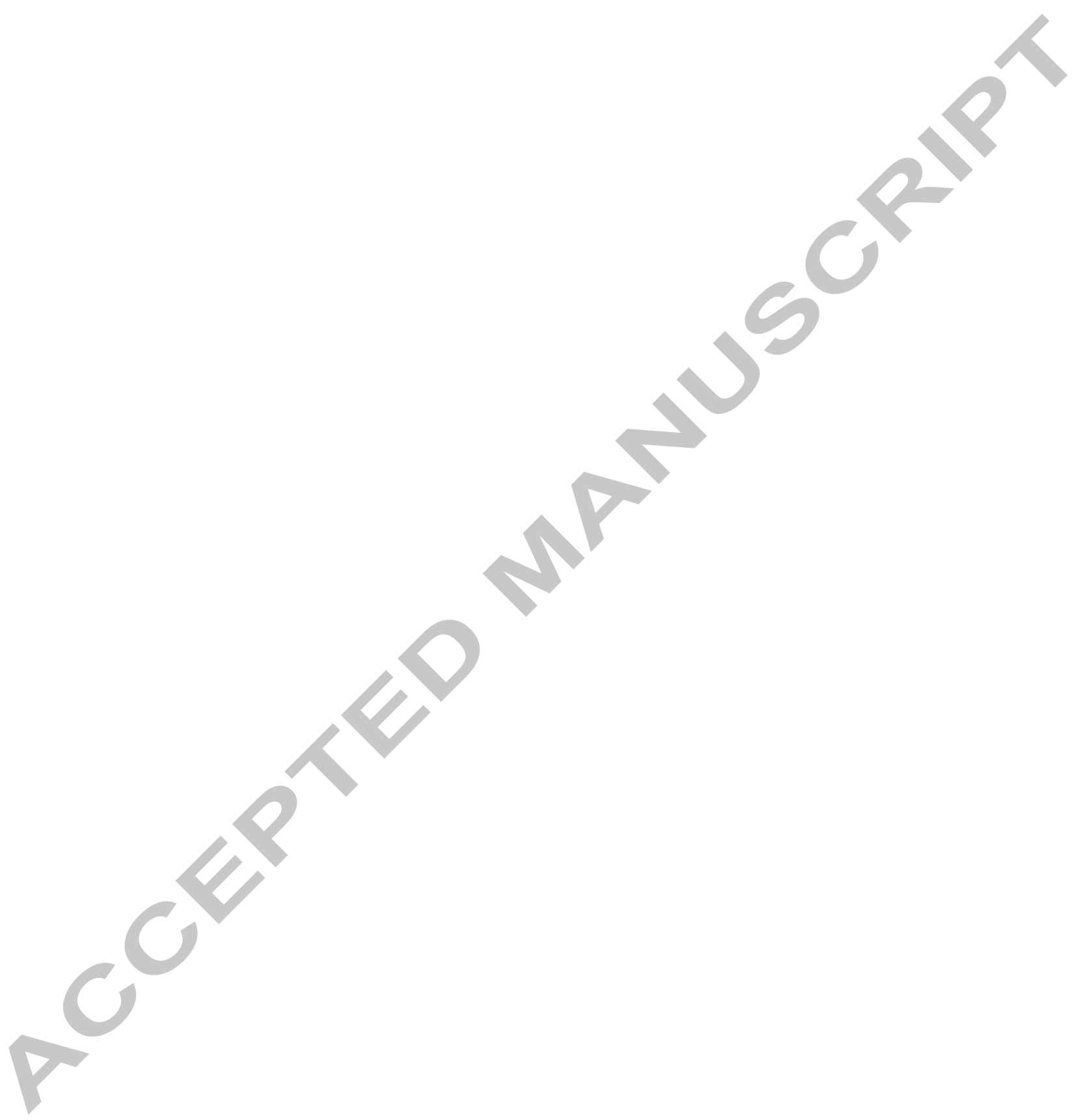


- $\alpha-\mathrm{Fe}_{2} \mathrm{O}_{3}$ hematite (JCPDS: $33-0664$ )

-..-. PCH-Si support

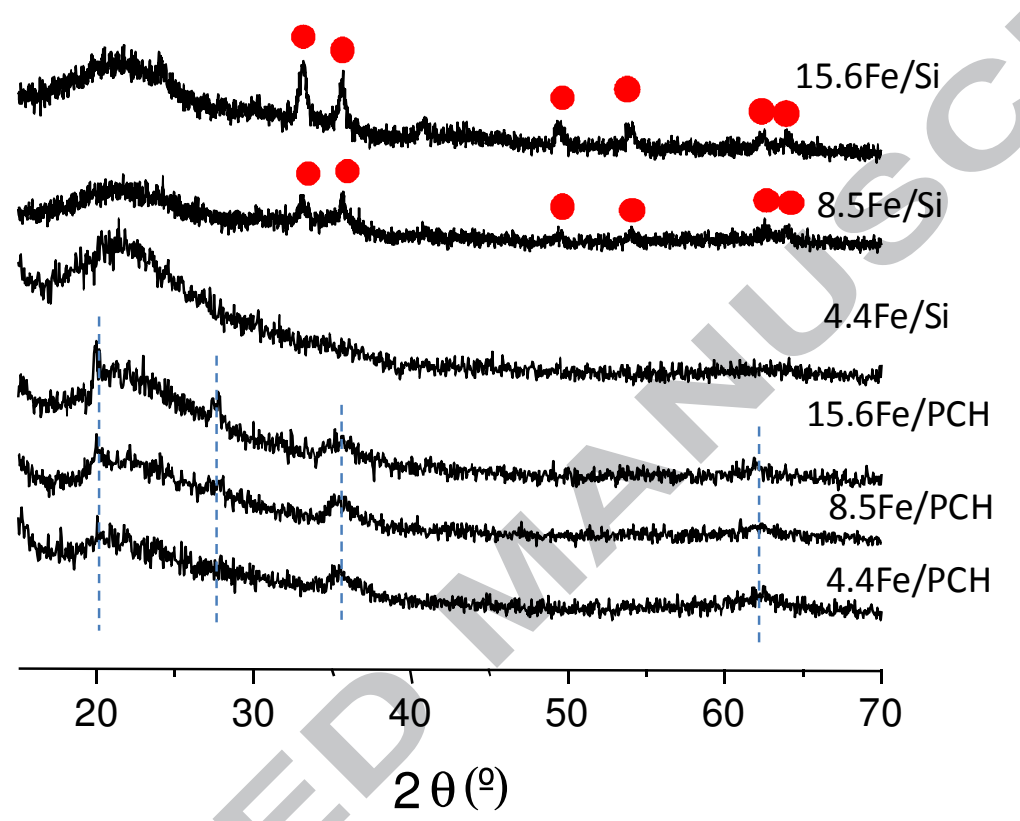

Fig. 1. XRD patterns of $\mathrm{xFe} / \mathrm{PCH}$ and $\mathrm{xFe} / \mathrm{Si}$ catalysts. 

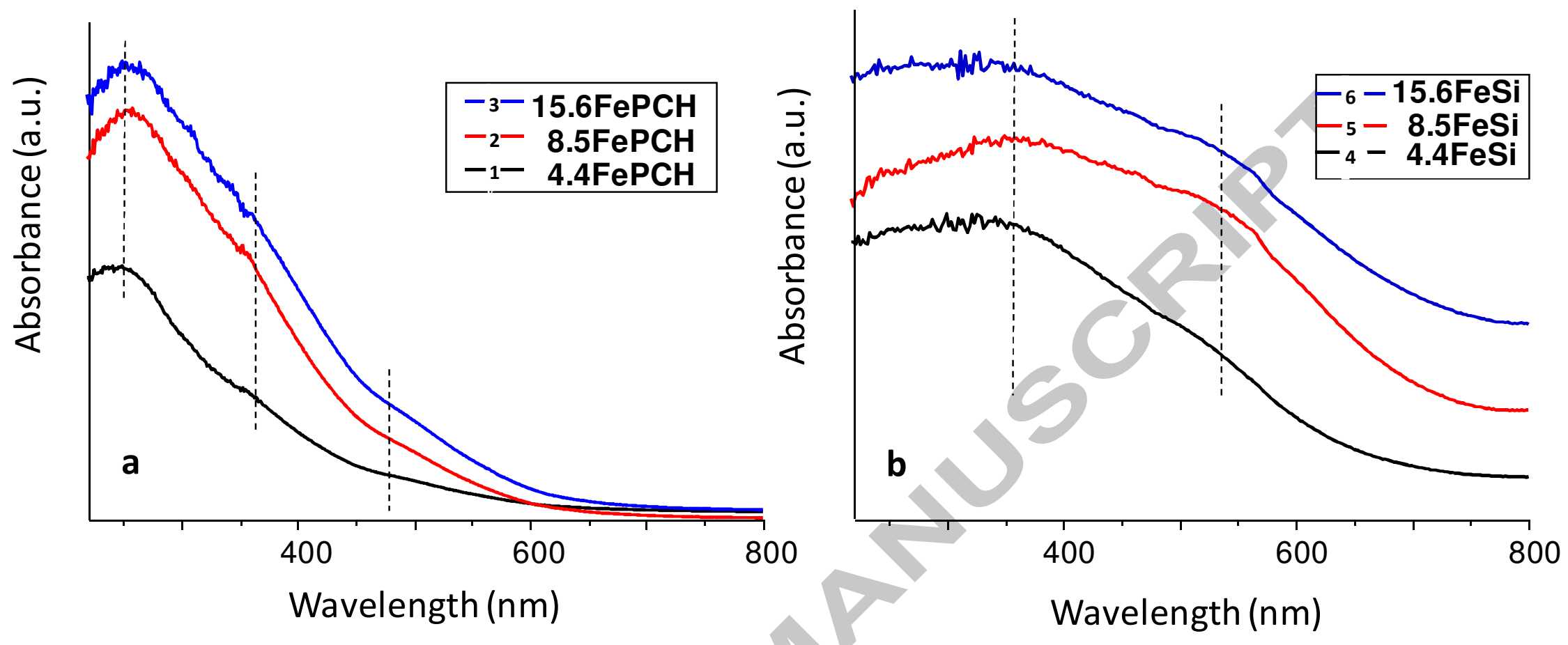

Fig.2. Diffuse reflectance UV-vis spectra of $\mathrm{xFe} / \mathrm{PCH}$ (a) and $\mathrm{xFe} / \mathrm{Si}$ (b) catalysts. 

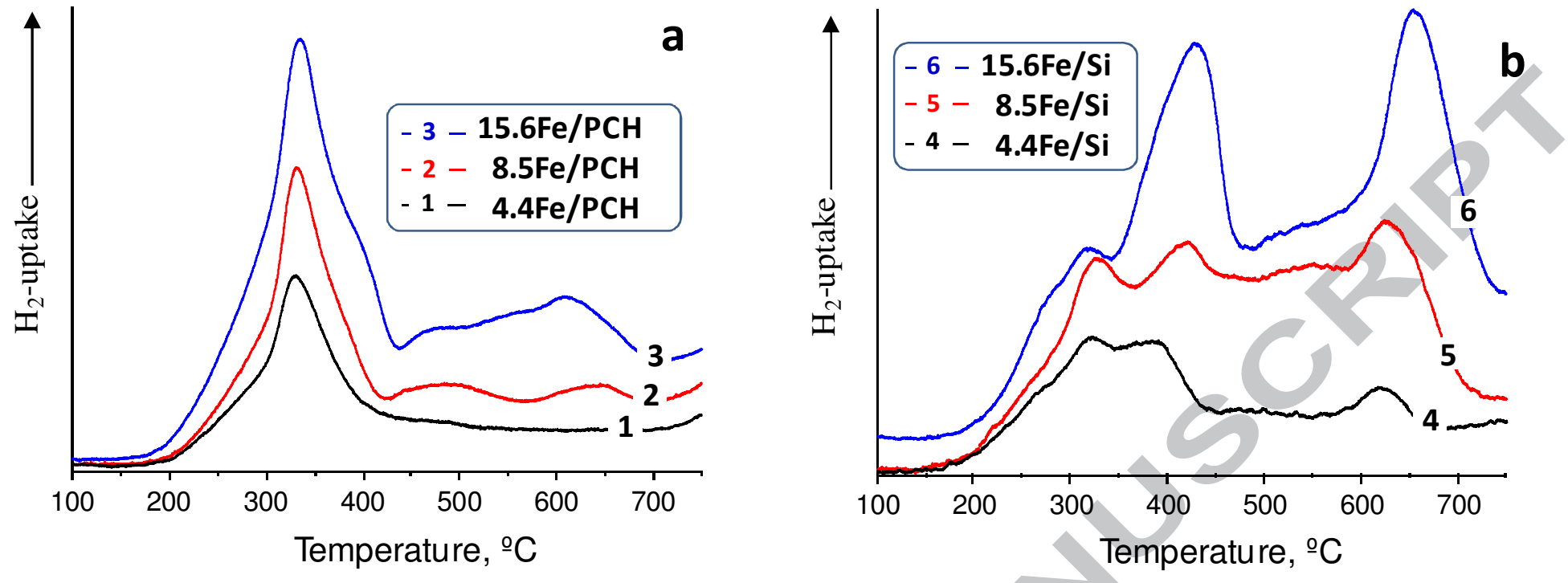

Fig.3. TPR- $\mathrm{H}_{2}$ profiles of $\mathrm{xFe} / \mathrm{PCH}(\mathrm{a})$ and $\mathrm{xFe} / \mathrm{Si}$ (b) catalysts. 

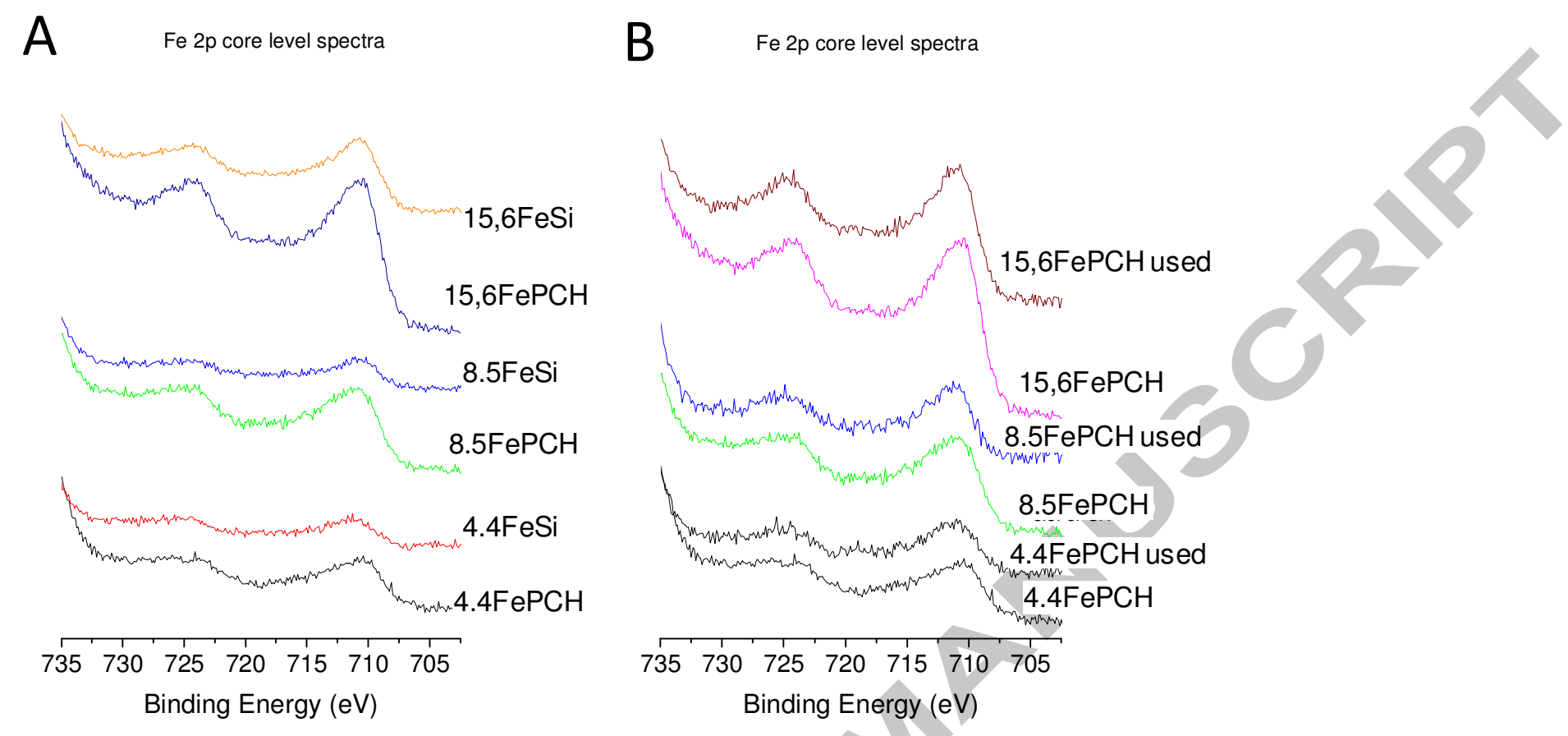

Fig. 4. Fe $2 p$ core level spectra of $\mathrm{A}$ ) iron oxide supported on a conventional amorphous silica and on the porous clay heterostructure (PCH) and B) iron oxides supported on $\mathrm{PCH}$ before and after use in $\mathrm{H}_{2} \mathrm{~S}$ oxidation (reaction conditions in text). 


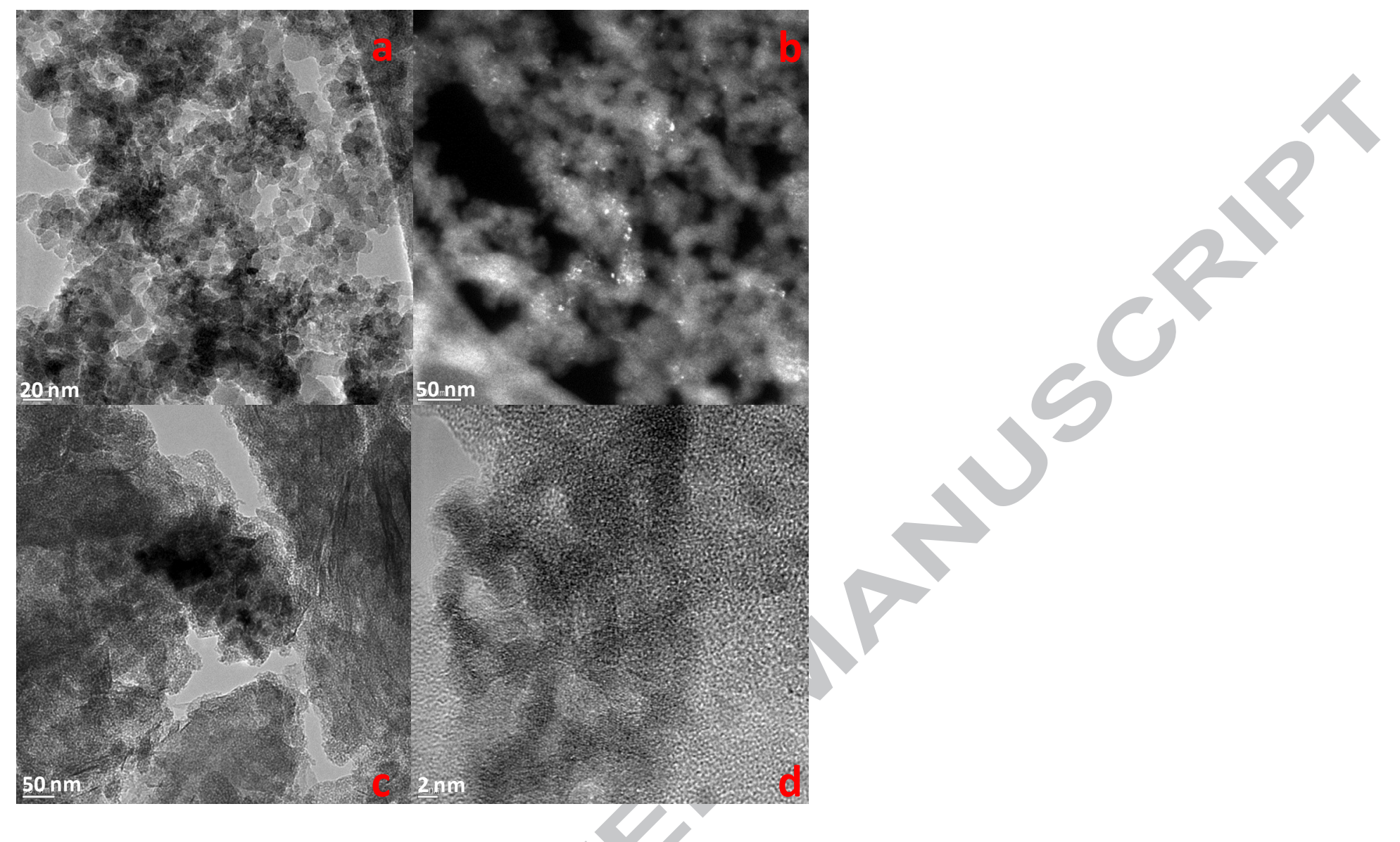

Fig.5. TEM study of 8.5FeSi catalyst (a TEM image, b bright field scan) and 8.5FePCH (c TEM image, d High Resolution TEM image). 

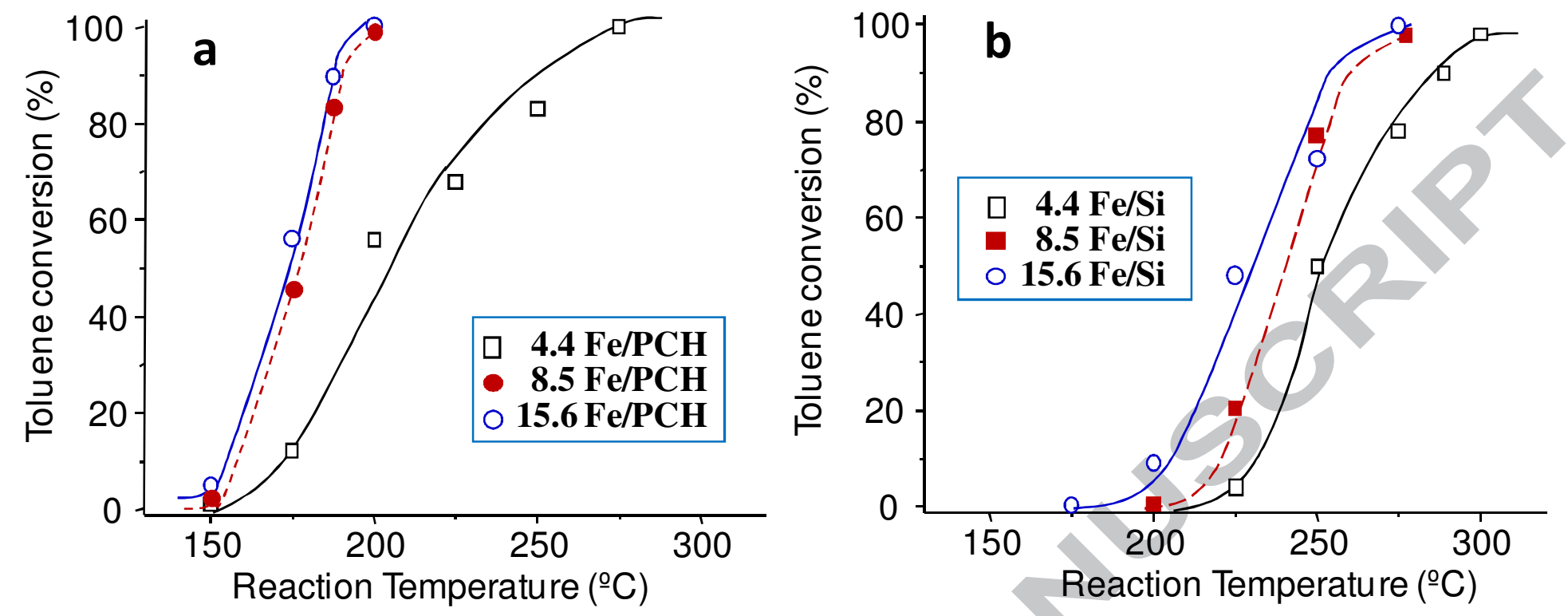

Fig.6. Variation of toluene conversion with reaction temperature achieved during the combustion of toluene over $\mathrm{xFe} / \mathrm{PCH}$ (a) or $\mathrm{xFe} / \mathrm{Si}$ (b) catalysts. Reaction conditions in text. 

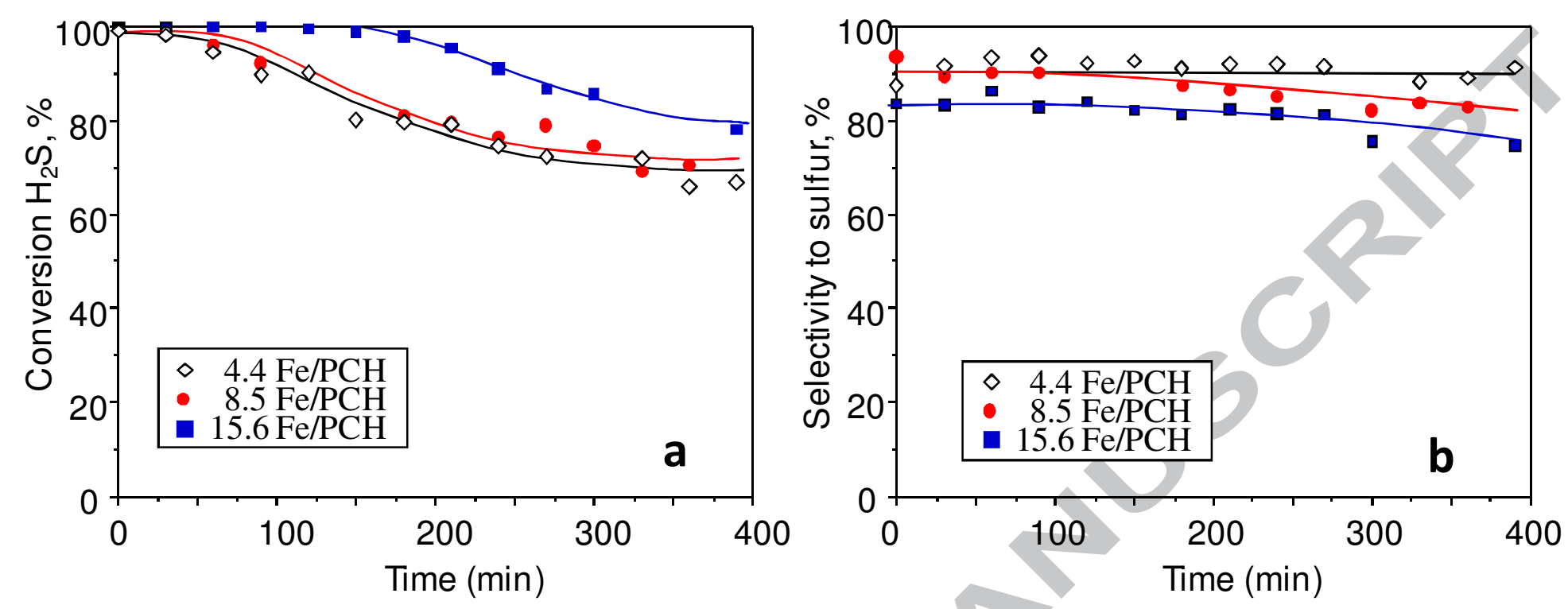

Fig. 7. Variation of $\mathrm{H}_{2} \mathrm{~S}$ conversion (a) and selectivity to sulfur (b) with time on stream achieved during the partial oxidation of $\mathrm{H}_{2} \mathrm{~S}$ over $\mathrm{xFe} / \mathrm{PCH}$ catalysts. Reaction conditions in text, $\left(\mathrm{W} / \mathrm{F}=32.6 \mathrm{~g}_{\mathrm{cat}} \mathrm{h} \mathrm{mol}^{-1}\right)$. 


\section{ACCEPTED MANUSCRIPT}
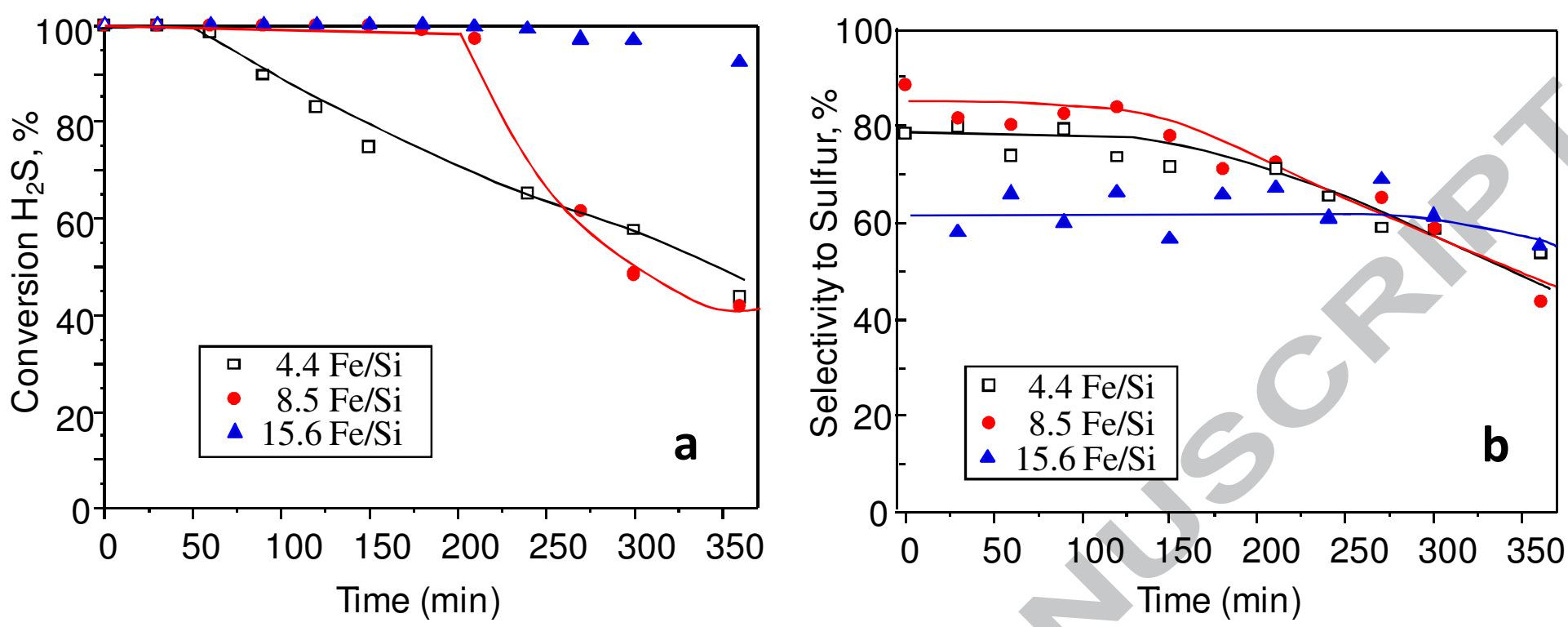

Fig. 8. Variation of $\mathrm{H}_{2} \mathrm{~S}$ conversion (a) and selectivity to sulfur (b) with time on stream achieved during the partial oxidation of $\mathrm{H}_{2} \mathrm{~S}$ over $x \mathrm{Fe} / \mathrm{Si}$ catalysts. Reaction conditions in text, $\left(\mathrm{W} / \mathrm{F}=65.2 \mathrm{~g}_{\mathrm{cat}} \mathrm{h} \mathrm{mol}{ }^{-1}\right)$. 


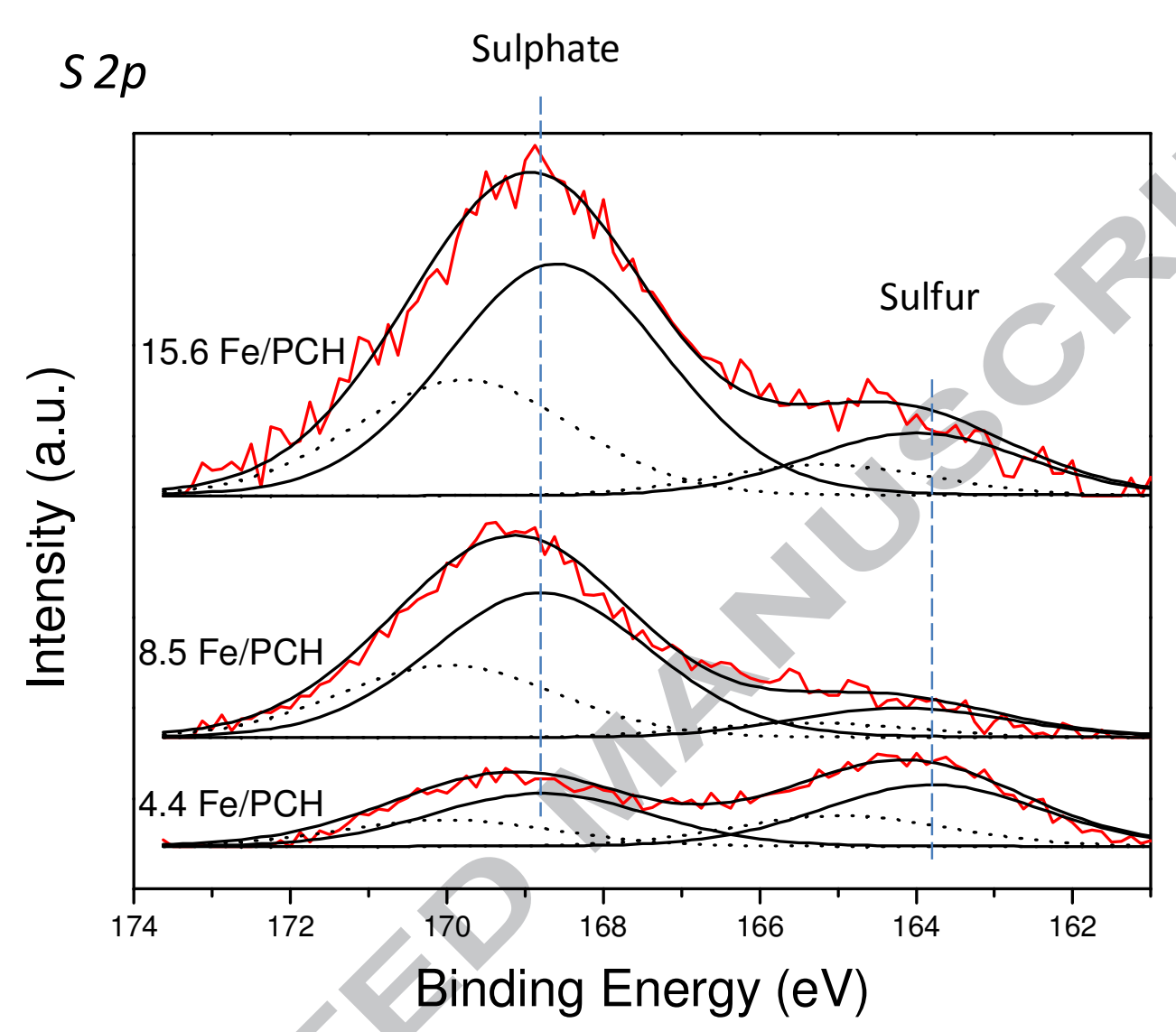

Fig. 9. S 2p core level spectra of iron oxide catalysts supported on $\mathrm{PCH}$. 


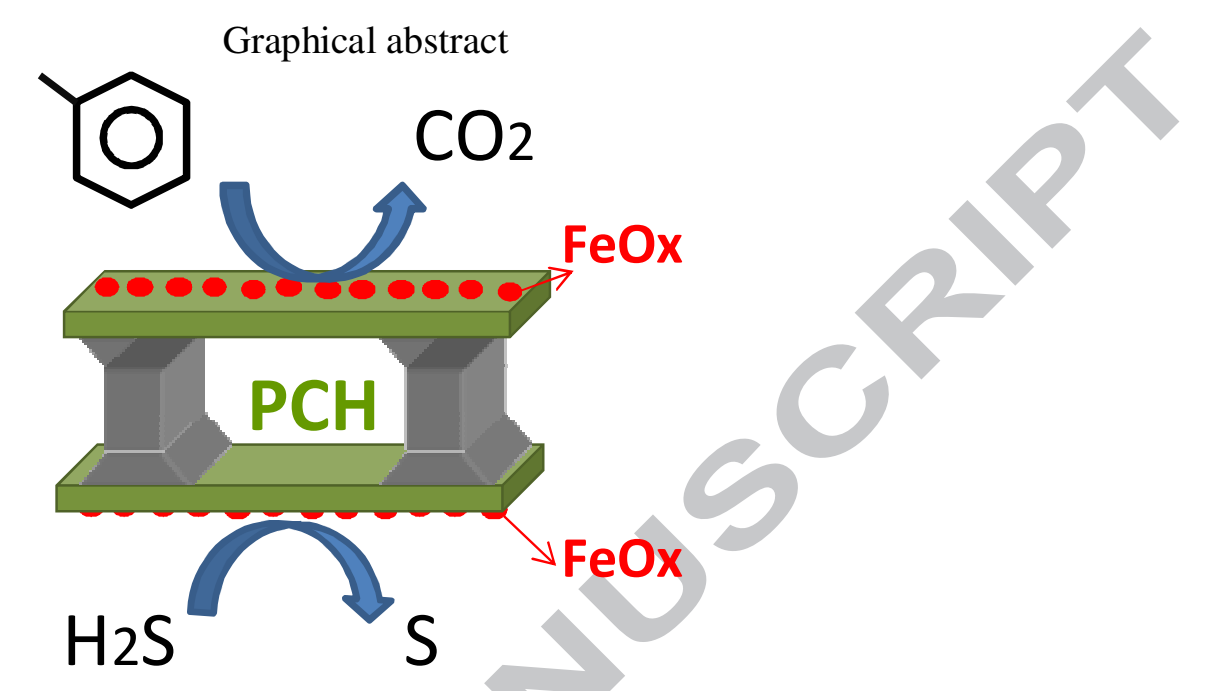




\section{Highlights}

- Porous Clays Heterostructures (PCH) favours dispersion of iron species

- $\mathrm{Fe} / \mathrm{PCH}$ presents high activity in toluene oxidation and in $\mathrm{H}_{2} \mathrm{~S}$ conversion

- $\mathrm{Fe} / \mathrm{PCH}$ higher activity than pure $\mathrm{Fe}_{2} \mathrm{O}_{3}$ and Fe/silica

- High selectivity to $\mathrm{S}$ in the $\mathrm{H}_{2} \mathrm{~S}$ oxidation and good stability 